\title{
Spatial and temporal variability of microbial communities and salt distributions across an aridity gradient before and after heavy rains in the Atacama Desert
}

\author{
Jianxun Shen 1,*, Timothy B. Shirey ${ }^{2}$, Adam J. Wyness ${ }^{3,4}$, Mark W. Claire ${ }^{1}$, Aubrey L. Zerkle ${ }^{1}$ \\ ${ }^{1}$ School of Earth and Environmental Sciences and Centre for Exoplanet Science, University of St Andrews, St \\ Andrews KY16 9AL, UK \\ 2 Biotechnology and Planetary Protection Group, Jet Propulsion Laboratory, California Institute of Technology, \\ Pasadena, CA 91109, USA \\ ${ }^{3}$ Sediment Ecology Research Group, Scottish Oceans Institute, School of Biology, University of St Andrews, St \\ Andrews KY16 8LB, UK \\ ${ }^{4}$ Coastal Research Group, Department of Zoology and Entomology, Rhodes University, Grahamstown 6139, \\ South Africa \\ * Correspondence: js365@st-andrews.ac.uk
}

\begin{abstract}
Over the past 150 million years, the hyperarid core of the Atacama Desert has been transformed by geologic and atmospheric conditions into one of the most unique and inhospitable landscapes on the planet. This makes it an ideal Mars analog that has been explored for decades as preliminary studies on the space life discovery. However, two heavy rainfalls that occurred in the Atacama in 2015 and 2017 provide a unique opportunity to study the response of resident extremophiles to rapid environmental change associated with excessive water and salt shock. Here we combine geochemical analyses with molecular biology to study the variations in salts and microbial communities along an aridity gradient, and to examine the reshuffling of hyperarid microbiomes before and after the two rainfall events. Analysis of microbial community composition revealed that soils within the southern desert were consistently dominated by Actinobacteria, Proteobacteria, Acidobacteria, Planctomycetes, Chloroflexi, Bacteroidetes, Gemmatimonadetes, and Verrucomicrobia; soils within the hyperarid sites were dominated by Aquificae and Deinococcus-Thermus before heavy rainfalls, while these organisms almost totally diminished after rainfall, and the hyperarid microbial consortia and metabolisms transformed to a more southern desert pattern along with increased biodiversity. Salts at the shallow subsurface were dissolved and leached down to a deeper layer, both benefitting and challenging indigenous microorganisms with the excessive input of water and ions. Microbial viability was found to change with aridity and rainfall events but correlated with elevation, $\mathrm{pH}$, conductivity, chloride, nitrate, sulfate, and soil organic matters (SOM). Metagenomic functional pathways related to stressor responses also increased in post-rainfall hyperarid soils. Our findings contribute to the primary goal of Atacama Mars analog research for understanding the microbial community structure and adaptations:
\end{abstract}


this study sheds light on the structure of xerophilic, halophilic, and radioresistant microbiomes in hyperarid environments, and their response to changes in water availability.

Keywords: microbiome; water stress; adaptation; function prediction; microbial network topology; extremophiles

\section{Introduction}

The Atacama Desert in northern Chile is the driest non-polar terrestrial desert on Earth, and was selected as an exobiology-relevant environment by the U.S. National Aeronautics and Space Administration (NASA) prior to the Mars Viking program (Cameron 1969; Gómez-Silva et al. 2008; Warren-Rhodes et al. 2019). The Atacama Desert spans more than 1,000 km in length from central Chile to southern Peru, and holds the longest continuous record of arid to hyperarid conditions on Earth (Hartley et al. 2005). It is widely accepted as a Mars analog system based on its similar geomorphic landscape to Mars and multiple physicochemical aspects such as its hyperaridity, absence of water weathering, high ultraviolet (UV) radiation, low levels of organic carbon, and large reservoirs of oxidants (Clark and Vanhart 1981; Heldmann et al. 2010; Kounaves et al. 2014; Navarro-Gonzalez et al. 2003; Quinn et al. 2005; Stepinski and Stepinski 2005; Sun et al. 2018). The essential nutrients to most mesophilic organisms are exhausted by the extreme environmental conditions there. These inhospitable conditions are the limit of life on earth (Neilson et al. 2012), and are analogous to the more recent dry Mars (Navarro-Gonzalez et al. 2003). Microbial life here is unique from other terrestrial locations because these organisms have been exposed to extreme surrounding for millions of years, since the late Jurassic (Hartley et al. 2005). Therefore, understanding the microbial community structure and adaptations is a primary goal of Atacama Mars analog research (Warren-Rhodes et al. 2019).

The onset of aridity in the Atacama Desert is attributed primarily to the combined effects of the cold Peru Humboldt current, a strong Pacific high-pressure zone, and a sandwiched rain shadow effect of the Western Andean and Coastal Cordillera (Hartley et al. 2005; Houston and Hartley 2003; Trewartha 1981). From north to south, a precipitation gradient exists along the desert strip, increasing from $\sim 0.1$ up to $100 \mathrm{~mm} / \mathrm{yr}$ (Houston 2006; Warren-Rhodes et al. 2006). At its driest, the Atacama Desert is 50 times more arid than the driest region in North America - the Californian Death Valley (Francaviglia 2016). The increased precipitation of the southern Atacama is primarily attributable to the coastal fog, known locally as camanchaca, which is advected from the sea to the Coastal Cordillera. The camanchaca is then capable of invading the Central Depression of the Atacama Desert through mountain corridors and over peaks with elevations less than 1,000 m (Cereceda et al. 2008; Warren-Rhodes et al. 2006). 
Although still extremely dry, soils of the southern Atacama Desert sustain large vascular plant and animal communities, some of which are not found at lower latitudes. Thus, the environmental gradients within the Atacama Desert serve as an excellent model to investigate the influence of long-term aridity and different frequencies of precipitation-led water stress on soil microbial communities.

The newly available Atacama Database of microbiology (Contador et al. 2019) records 2,302 microorganisms in the Atacama Desert, with reference to 633 previously published papers between 1966 and 2016 (Bull et al. 2016). Among these microorganisms, 1,741 species are from the Domain Bacteria. These bacteria belong to 20 different phyla, including Acetothermia, Acidobacteria, Actinobacteria, Atribacteria, Bacteroidetes, Chloroflexi, Cyanobacteria, Deinococcus-Thermus, Firmicutes, Gemmatimonadetes, Gracilibacteria, Latescibacteria, Nitrospirae, Parcubacteria, Planctomycetes, Proteobacteria, Saccharibacteria, Spirochaetes, Synergistetes, and Verrucomicrobia. However, the diversity of uncultured bacteria clones from unknown phyla still dominate $40 \%$ of the currently known Atacama microbiome. Of the known phyla, Proteobacteria, Cyanobacteria, Actinobacteria, Firmicutes, and Bacteroidetes are the most common phyla that occupy $18 \%, 11 \%, 10 \%$, $10 \%$, and $8 \%$ of bacterial communities, respectively. In addition, 294 species of Archaea were recorded in the Atacama Database. Euryarchaeota are undoubtedly the dominant archaeal phyla (53\%), 90\% of which are members of the Class Halobacteria. $44 \%$ of the total archaeal phyla are unknown, and the remaining 3\% are Crenarchaeota and Nanohaloarchaeota (Contador et al. 2019). These microbes are distributed throughout the soil profile, with surface inhabitants are generally more tolerant to strong UV radiation, and those found deeper in soils are more tolerant to hypersaline conditions (SchulzeMakuch et al. 2018).

Historically, studies of microbial communities in the Atacama have focused on locations within the hyperarid region of the desert (Azua-Bustos et al. 2015; Azua-Bustos et al. 2018; Azua-Bustos et al. 2019; Bagaley 2006; Connon et al. 2007; Drees et al. 2006; Fernandez-Martinez et al. 2019; Finstad et al. 2017; Lester et al. 2007; Neilson et al. 2017; Neilson et al. 2012; Roldan et al. 2014; Schulze-Makuch et al. 2018; Uritskiy et al. 2019; Warren-Rhodes et al. 2019; Wierzchos et al. 2011; Wierzchos et al. 2012), with few studies examining the soil microbial communities of the more humid southern region (latitude $>25^{\circ} \mathrm{S}$ ). In contrast to the reduced microbial biomass and low activity common in hyperarid soils of the north, soils of the southern Atacama support more diverse and abundant microbial communities (NavarroGonzalez et al. 2003) that facilitate nutrient cycling and increase the mineralization of organic compounds (Goldstein et al. 1999; Puente et al. 2009).

Microorganisms of desert ecosystems have evolved a myriad of evolutionary adaptations to cope with associated environmental pressures (Dose et al. 2001; Zahran 1997). Despite of the extreme aridity, 
desiccation may not be the sole or even the primary factor influencing microbial life in desert environments (Hullar et al. 1996; Navarro-Gonzalez et al. 2003; Quinn et al. 2005; Reynolds et al. 2004; Schwinning et al. 2004; Shen et al. 2019; Shirey et al. 2012). Counter-intuitively, an abrupt increase in water availability in hyperarid soils is extremely harmful to xerophilic microorganisms because these cells are induced to transform from the defensive or dormant state to the metabolically active state while unexpectedly being exposed to attack from extreme temperature and UV radiation (Cockell et al. 2017). In addition, excessive water causes high osmotic shock to the microbial semipermeable membrane and disturbs their survival strategies adapted for limited moisture (Azua-Bustos et al. 2018; Stevenson et al. 2015). After the heavy rainfall in 2017 at the core region of the Atacama Desert, 75-87\% of pre-rainfall species disappeared, and no viable archaea or eukaryotes were detected in undrained brines (Azua-Bustos et al. 2018). Although these rainfall events can severely damage the extremotolerant microbial communities, previous studies demonstrated that the community structure can recover as soon as one month after, or up to more than one year (Armstrong et al. 2016; Uritskiy et al. 2019), using a variety of biochemical mechanisms and osmoregulatory systems (Wood 2015). Instantaneously after rainfall, microorganisms start producing proteins and metabolites that are crucial in fundamental biosynthetic pathways, energy supplements, desiccation resistance, radiation protection, and oxidation defense for the preparation of the upcoming hyperarid period (FernandezMartinez et al. 2019).

Mars is likely to have been a much wetter planet around 4 billion years ago. Between then and the drier planet we recognize today, a transition dry period with occasional moisture may have occurred (Ramirez and Craddock 2018). Detection results by the Curiosity rover show evidence of temporary subsurface liquid during night-time on equatorial Mars and possibly beyond (Martin-Torres et al. 2015). Therefore, the rare heavy rains in the hyperarid Atacama act as an analog to the transient availability of liquid water on Mars. In this study, we compared the differences in microbiome and soil salt compositions along a precipitation gradient of the Atacama Desert before and after two heavy rainfall events. Environmental factors were identified to investigate their impacts on local microbial communities. We used these data to understand the natural microbial compositions, networks, metabolisms, and adaptations to water perturbation in terms of both spatial and temporal variability. Our results also highlight the environmental conditions that most impact microbial communities in hyperarid and less arid transition sites of the Atacama Desert, and the effects those conditions exert on the microbial communities within the two regions.

\section{Materials and Methods}

\subsection{Site descriptions}


Samples were collected from the Atacama Desert, northern Chile, in 2012 and 2017. During May 29 to June 12, 2012, soils were collected from eight field sites along a $1,000-\mathrm{km}$ north to south latitudinal transect from $20^{\circ} \mathrm{S}$ to $30^{\circ} \mathrm{S}$. Samples were obtained from four hyperarid sites (KM40 [ 40 km south of Iquique], María Elena South [MES], Point of No Return [PONR], and Yungay) and six arid sites from the transition zone (Transition Zone 4 to 9 [TZ-4 to TZ-9]) (Figure 1). Visible vegetation cover started appearing from TZ-5 to TZ-9. One sampling pit was randomly dug at each site; triplicate samples were collected at a depth of about $20 \mathrm{~cm}$ from each pit and then homogenized. All samples were collected with a sterile sampling trowel, placed into sterile Whirl-Pak ${ }^{\circledR}$ bags (Nasco, Fort Atkinson, USA). Soils obtained in 2012 are collectively referred as AT-12.

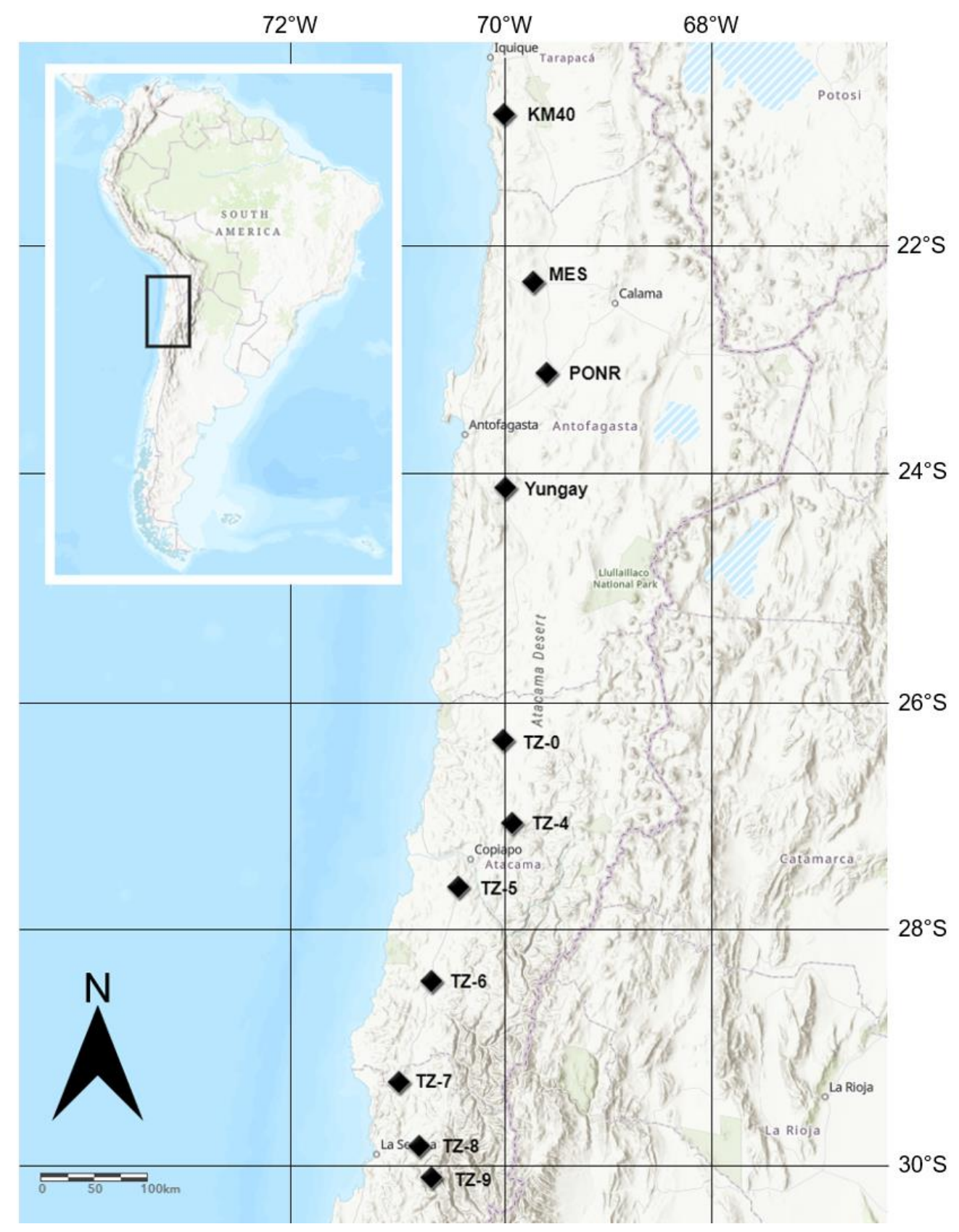


Figure 1. Geographic locations of the Atacama Desert sampling sites in 2012 and 2017, including KM40 ( 40 km south of Iquique), María Elena South (MES), PONR (Point of No Return), Yungay, Transition Zone 0 (TZ-0), and TZ-4 to TZ-9.

Two unprecedented heavy rainfalls expanded from the Yungay region during March 2015 (SchulzeMakuch et al. 2018) and June 2017 (Azua-Bustos et al. 2018) with $38.6 \mathrm{~mm}$ and $19.6 \mathrm{~mm}$ of rainfall respectively, according to the record at Antofagasta Rain Gauge $\left(23.5975^{\circ} \mathrm{S}, 70.3867^{\circ} \mathrm{W}\right.$, Altitude: $\left.50 \mathrm{~m}\right)$. Between November 30 and December 6, 2017, seven field sites at a longitudinal transect from $22^{\circ} \mathrm{S}$ to $29^{\circ} \mathrm{S}$ (Figure 1) were selected for sampling as described in Shen et al. (2019). Briefly, samples were obtained from three hyperarid sites (MES, PONR, and Yungay) and four transition sites (TZ-0, TZ-4, TZ-5, and TZ-6). Within each site, three pits were sampled in the same manner as AT-12 samples for geochemical analyses and DNA extractions, and the third sampling pit was additionally sampled for microbial cultivations. Similarly, soils obtained in 2017 are collectively referred as AT-17. The geographic locations, physicochemical properties, and local daily precipitation of each AT-17 study site during the 2017 heavy rainfall event was presented in Shen et al. (2019).

\subsection{Soil characterizations}

In order to characterize AT-12 samples for soil $\mathrm{pH}$ and conductivity measurements, triplicate soil slurries were prepared by adding $1 \mathrm{~g}$ of soil to an appropriate volume of deionized water. The $\mathrm{pH}$ and electrical conductivity were measured with a YSI Model 30 Handheld Salinity, Conductivity and Temperature System (YSI Inc., Yellow Springs, Ohio, USA) after $15 \mathrm{~min}$ agitation at $220 \mathrm{rpm}$ and settling for $5 \mathrm{~min}$. For carbon $(\mathrm{C})$ and nitrogen $(\mathrm{N})$ quantification, triplicate pre-dried $\left(100^{\circ} \mathrm{C}\right.$ overnight) AT-12 geochemical soil samples were ground in mortar and pestle. Soils were stored in $20 \mathrm{~mL}$ scintillation vials. Subsamples of $0.1 \mathrm{mg}$ were quantified for total soil $\mathrm{C}$ and $\mathrm{N}$ content in a Carlo Erba EA1108 (Isomass Scientific Inc., Calgary, Canada). Lastly, soil organic matter was determined as the loss of mass via ignition at $500^{\circ} \mathrm{C}$ after carbonates were removed using a 24 hour incubation at room temperature with $0.5 \mathrm{M} \mathrm{HCl}$.

General soil properties ( $\mathrm{pH}$, electrical conductivity, major sediment elements by X-ray fluorescence (XRF) methods, and the concentrations of total organic carbon (TOC), total organic nitrogen (TON), carbonate, and nitrate) of AT-17 geochemical samples were reported in Shen et al. (2019). SOM in AT17 samples were determined as the difference between the mass loss of ignition measured by XRF and the carbon dioxide loss calculated based on carbonate. Both AT-12 and AT-17 geochemical samples were sieved through $1.4 \mathrm{~mm}$ prior to ion chromatography for soluble anion determinations as described in Shen et al. (2019). 
Quantitative X-ray diffraction (XRD) analysis for AT-12 was reported in Harris et al. (2016). AT-17 soil samples for XRD were crushed using a Planetary Micro Mill (PULVERISETTE 6, FRITSCH) and sieved through a $355-\mu \mathrm{m}$ sieve. The mineralogy of these crushed and sieved samples was analyzed on a Philips X-Ray Diffractometer (PW1830 generator, PW1050/80 goniometer, PW1710 diffractometer) using Co $\mathrm{K} \alpha$ radiation. Generator settings for the measurement were $30 \mathrm{kV}, 30 \mathrm{~mA}, 3-70^{\circ}$ range $2 \theta$ scan, $0.01^{\circ}$ step, $1 \mathrm{~s} /$ step. Mineral phases were identified using the EVA 2 software from SOCABIM with the ICDD PDF-2 database.

\subsection{DNA extractions and sequencing}

AT-12 microbiological samples were stored at room temperature and extracted for DNA sequencing within 1 month. Triplicate $1 \mathrm{~g}$ of AT-12 microbiological soil samples from each site for DNA extractions were desalted with $1 \mathrm{~mL}$ sterile deionized water, followed by a wash with $10 \%$ sodium acetate and twice with deionized water. Samples were centrifuged at 3,000 $\times \mathrm{g}$ for $10 \mathrm{~min}$ and the supernatants were decanted after each wash. Total soil DNA was extracted from desalted samples using the MP Biomedicals $^{\mathrm{TM}}$ FastDNA ${ }^{\mathrm{TM}}$ SPIN Kit for Soil following a modified manufacturer's protocol: the cell lysis step was extended to an overnight incubation at $50^{\circ} \mathrm{C}$ with gentle agitation. Following extraction, the triplicate DNA extracts from each location were pooled to a final volume of $100 \mu$ l. DNA extracts were amplified for barcoded 454 pyrosequencing using Platinum ${ }^{\circledR}$ PCR Supermix (Invitrogen, USA) and $16 S$ rRNA primer pair 515F (5'-GTGCCAGCMGCCGCGGTAA-3') and 806R (5'GGACTACHVGGGTWTCTAAT-3') (Caporaso et al. 2012). $4 \mu$ l of DNA template was used in each PCR reaction and the final concentrations of primers in PCR mixtures were $125 \mathrm{nM}$. The PCR thermocycler steps were initially $94^{\circ} \mathrm{C}$ for $2 \mathrm{~min}$, followed by 30 cycles of $94^{\circ} \mathrm{C}$ for $30 \mathrm{~s}, 58^{\circ} \mathrm{C}$ for $30 \mathrm{~s}$, and $72^{\circ} \mathrm{C}$ for 60 sec, with a final extension of $6 \mathrm{~min}$ at $72^{\circ} \mathrm{C}$. The presence of target PCR amplicons was verified by running electrophoresis on a $1 \%$ agarose gel. Amplicon quantifications were assessed on a Qubit ${ }^{\circledR}$ fluorometer. The reaction mixture was purified with AMPure ${ }^{\circledR}$ XP PCR cleanup beads (Beckman Coulter, Brea, California, USA). 16S rRNA amplicons were submitted to the University of WisconsinMadison Biotechnology Center (https://www.biotech.wisc.edu/services/dnaseq) for sequencing on a 454 GS-FLX Titanium System (Roche, CT, USA). All implements for DNA extractions and sequencing were either filter sterilized, autoclaved, flamed, or UV-irradiated to prevent any external contamination; water was molecular biology grade and nuclease-free.

AT-17 samples for DNA extraction were stored for one year in a freezer. Due to the extreme aridness of these dry sand samples, the effect of the storage duration is expected to be insignificant (MiyamotoShinohara et al. 2000; Morgan et al. 2006). DNA of AT-17 microbiological samples from three pits of each site were extracted using the MP Biomedicals ${ }^{\mathrm{TM}}$ FastDNA $^{\text {TM }}$ SPIN Kit for Soil following a modified 
manufacturer's protocol: during the cell lysis step, mixtures were incubated at room temperature for 1 hour. DNA extracts were amplified in triplicate for barcoded Illumina 165 metagenomic sequencing using KAPA HiFi HotStart ReadyMix (KAPA Biosystems, Roche, UK) and $16 \mathrm{~S}$ rRNA primer pair 341F, 5'-CCTACGGGNGGCWGCAG-3', and 785R, 5'-GACTACHVGGGTATCTAATCC-3' (Herlemann et al. 2011; Klindworth et al. 2013) using the Nextera index kit (Illumina $\left.{ }^{\circledR}\right)$. Amplicons were quantified using an Invitrogen ${ }^{\mathrm{TM}}$ Qubit ${ }^{\mathrm{TM}} 3.0$ Fluorometer. Triplicate amplicons from each pit were pooled together and concentrated by heating at $50^{\circ} \mathrm{C}$ to a final volume of $50 \mu 1$. 16S rRNA amplicons for Illumina MiSeq System was replicated and sequenced by following 165 Metagenomic Sequencing Library Preparation (Illumina ${ }^{\circledR} 2013$ ) together with a $20 \%$ PhiX control using paired-end 300 bp reads with v3 Chemistry, modified by extending the amplicon PCR reactions from 25 to 29 cycles due to low product yield.

\subsection{Assessments of bacterial abundance and viability}

Viable, non-viable, and total bacterial cells in AT-12 samples were enumerated by flow cytometry at the College of Veterinary Medicine, Auburn University (Auburn, Alabama, USA) within one month of sample collection. Triplicate soils from each site were gently shaken with bacterial detachment medium (10-6 M Zwittergent ${ }^{\circledR}$ 3-12 detergent, 10-3 M ethylenediaminetetraacetic acid (EDTA), and 0.01\% peptone in $10 \%$ phosphate buffered saline (PBS) solution) overnight at room temperature. The mixture was settled for $15 \mathrm{~min}$ and the liquid portion was filtered through a Whatman ${ }^{\circledR}$ qualitative filter paper, Grade 2. The recovered filtrate was centrifuged for $10 \mathrm{~min}$ at 3,000 $\times \mathrm{g}$ to collect cell pellets. The quality of cell pellet collection was evaluated by 4',6-diamidino-2-phenylindole (DAPI) fluorescence imaging of the supernatant of recovered filtrate. Cell pellets were resuspended in PBS and stained for propidium iodine and SYTO ${ }^{\circledR} 9$ fluorochromes using the LIVE/DEAD ${ }^{\circledR}$ BacLight ${ }^{\mathrm{TM}}$ Bacterial Viability kit (Molecular Probes Inc., Eugene, Oregon, USA). The total microbial concentrations and viability were assessed on an Accuri ${ }^{\mathrm{TM}}$ C6 Flow Cytometer (BD Biosciences).

The abundance and viability of AT-17 microbial communities were analyzed via duplicate trypan blue staining assay within one month of samples collection, and cultivation methods within one month and replicate within half a year after sample collection. Duplicate AT-17 microbiological soils were suspended, and 10× serially diluted two to four times to clear out any sand particles. $0.4 \%$ Trypan blue was added to $9 \times$ of the dilute solution. Viable (non-colored) and non-viable (blue) microbial cells were mounted on a Hirschmann Instruments ${ }^{\mathrm{TM}}$ Counting Chamber and counted using oil immersion light microscopy (AmScope). Detailed microbial cultivations of AT-17 samples were elucidated in Shen et al. (2019). Briefly, duplicate AT-17 samples from each site were suspended and homogenized in 1× volume of sterilized ultrapure water for microbial cultivations. An appropriate amount of soil 
suspension was spread on three types of culture medium: tryptic soy agar plate, Luria-Bertani (LB) agar plate, and plate count agar. Visible colonies were counted after 20 days of incubation at $21^{\circ} \mathrm{C}$.

\subsection{Salt and water amendments}

To inspect the effects of a variety of excessive dissolved salts on the viable microbial community, soils from each site were amended with salt solutions. Solutions of $10 \%$ Sodium chloride, $10 \%$ sodium sulfate, $10 \%$ sodium carbonate, $10 \%$ sodium acetate, and $10 \%$ sodium L-lactate were prepared in ultrapure water and autoclaved at $121^{\circ} \mathrm{C}$ for $30 \mathrm{~min}$. After cooling to room temperature, $10 \mathrm{~g}$ of AT-12 soil was combined with the salt solution for 4 days at $21^{\circ} \mathrm{C}$ (Shen et al. 2019). Duplicate salt-amended soils were suspended in appropriate volume of sterile ultrapure water and spread on tryptic soy agar, LB agar, and plate count agar plates. Plates were sealed with Bemis ${ }^{\mathrm{TM}}$ Parafilm $^{\mathrm{TM}} \mathrm{M}$ Laboratory Wrapping Film and incubated for 20 days at $21^{\circ} \mathrm{C}$ prior to cell counting (Bagaley 2006). Colony forming units (CFUs) were determined by the multiplication of the number of colonies, dilution factor, and 1.45 to account for the addition of $4.5 \mathrm{~mL}$ solution to $10 \mathrm{~g}$ soil.

In addition, $4.5 \mathrm{~mL}, 3 \mathrm{~mL}$, and $1.5 \mathrm{~mL}$ of sterile ultrapure water was added to each $10 \mathrm{~g}$ of AT-17 microbiological samples, which covers about the 1/3,2/3, and full of soil area, respectively. Since the bottom diameter of Petri dishes used for culturing experiments is $90 \mathrm{~mm}$, these volumes of water are equivalent to approximately $0.24,0.47$, and $0.71 \mathrm{~mm}$ daily precipitation, respectively. CFUs were cultured and determined in the same manner as salt amendments. CFUs from cultivation experiments were converted via common logarithmic transformation. CFUs on salt amendments were standardized by subtracting their respective $4.5-\mathrm{mL}$ water amendment groups; and CFUs on water amendments were standardized by subtracting their corresponding groups without any amendments.

\subsection{Data analyses}

Multiplex 454 sequence reads of AT-12 bacterial sequencing results were pre-processed with the open source package Quantitative Insights into Microbial Ecology (QIIME) (Caporaso et al. 2010b). Reads were filtered by removing those of low quality, with ambiguous characters and missing barcoded primers, of a length less than 150 base pairs, and with quality scores lower than 25 . The remaining reads were aligned using Python Nearest Alignment Space Determination (PyNAST) (Caporaso et al. 2010a). Illunima-sequenced AT-17 bacterial reads were combined and demultiplexed into Casava 1.8 pairedend format with QIIME 2 (Bolyen et al. 2019). Reads of low quality were denoised with DADA2 (Callahan et al. 2016). Reads were filtered by trimming the first 13 base pairs and removing those of low quality, with ambiguous characters and missing barcoded primers, of a length less than 300 base pairs. AT-12 and AT-17 sequences were then dereplicated, merged, and further analyzed together in QIIME 
2. Merged AT-12/ 17 sequences were clustered into operational taxonomic units (OTUs) at a 99\% similarity cutoff. The quality of total clustered sequences was double confirmed via noise and chimera pattern checking by VSEARCH (Rognes et al. 2016) and UCHIME (Edgar et al. 2011).

The representative taxonomic identities were aligned at $99 \%$ full-length sequence homology using pretrained naïve Bayes classifier based on SILVA 132 marker gene reference database (Quast et al. 2013): the primer pair used to extract reference reads are 341F $5^{\prime}$-CCTACGGGNGGCWGCAG-3' and the combinative reverse primer 5'-GACTACHVGGGTWTCTAAT-3' as a conjunction of the 16S rRNA gene regions used for AT-12 and AT-17 sequencing. The reverse primers - 785R, 806R, and combinative reverse primer - were compared in silico for differences in bacteria identification using the probe match webtool at the Ribosomal Database Project (https://rdp.cme.msu.edu/probematch) (Cole et al. 2014). These three reverse primers matched 11,958, 11,857, and 11,970 type species of 30 identical bacterial phyla, respectively. Therefore, bias in the results due to the two different primer pairs was insignificant.

OTU tables were rarefied to remove sampling depth heterogeneity at 1,186 even sampling depth. Alpha diversity indices (binary logarithmic Shannon diversity, Faith's phylogenetic diversity, Pielou's Evenness, and observed OTUs) were computed with the alpha-phylogenetic package (Faith 1992) of QIIME 2. Alpha rarefaction curves were generated at the maximum 5,000 sequencing depth. Characteristic bacterial phyla associated with the sampling year and aridity were predicted and clustered with the q2-sample-classifier package (Bokulich et al. 2018) showing the 100 most representative sequences. Analysis of composition of microbiomes (ANCOM) was employed to determine the genera that were significantly different among sampling year and aridity (Mandal et al. 2015). Hierarchical clustering and principal coordinate analysis (PCoA) of each individual site using Bray-Curtis distance matrix were performed in Past 3.26 (Hammer et al. 2001). Principal component analysis (PCA) of environmental variables based on the correlation matrix was performed in OriginPro 2019.

Enzyme prediction and functional annotation of constructed sequences were performed in software Phylogenetic Investigation of Communities by Reconstruction of Unobserved States 2 (PICRUSt2) based on marker gene sequences (Douglas et al. 2019). The abundance of predicted functional pathways was standardized as the percentage of the sum of read depths. MetaCyc pathway identifiers were linked to their respective functions at the secondary superclass level using MetaCyc pathway hierarchy system (Caspi et al. 2018).

Finally, since microbial community network closely links with their ecosystem function (Finlay et al. 1997), we conducted network analysis on Atacama microbiota based on OTU numbers. AT-12 and AT17 samples were combined for the valid Spearman's rank correlation analysis, and then divided into 5 
hyperarid sites (AT-12 KM40, AT-12 Yungay, and 3 pits of AT-17 MES) and 17 transition sites (AT-12 TZ-4, AT-12 TZ-5, AT-12 TZ-6, AT-12 TZ-7, AT-12 TZ-8, AT-12 TZ-9, 2 pits of AT-17 TZ-0, 3 pits of AT17 TZ-4, 3 pits of AT-17 TZ-5, and 3 pits of AT-17 TZ-6). OTUs with abundance of less than $0.001 \%$ of the total number of OTUs were removed, resulting in a final subset of 988 OTUs from the hyperarid core and of 8,636 OTUs from the transition zone. Using individual OTUs and intercorrelation as nodes and connecting edges respectively, the co-occurrence pattern of OTUs that represents microbial network was defined based on their Spearman correlation coefficients calculated by the Hmisc package (Harrell 2019) of R (https://www.r-project.org/). Co-occurrence was regarded as reliable when the Spearman correlation coefficient was both greater than 0.6 and statistically significant at $p<0.01$ (Barberan et al. 2012; Junker and Schreiber 2008). Network diagram was drawn and network statistics (i.e., edge number, cumulative degree distribution of nodes, average path length, eigenvector centrality, centralization of graph according to node betweenness, and modularity) were computed using the igraph package (Csardi and Nepusz 2006) of R.

\section{Results}

\subsection{Soil geochemical features}

To investigate Atacama soil physicochemical context, samples were analyzed by total $\mathrm{C}, \mathrm{N}$, and soil organic matter (SOM) quantifications, X-ray diffraction (XRD), X-ray fluorescence (XRF), and ion chromatography (IC). In AT-12 soils before heavy rainfalls, the $\mathrm{pH}$ ranged from 8.0 to 9.5 , with the lowest $\mathrm{pH}$ in KM40 and the highest in TZ-5. Electrical conductivity of AT-12 ranged from 0.03 to 22.30 $\mathrm{mS} / \mathrm{cm}$, with the highest conductivity in KM40. Soil carbon content ranged from $0.1 \%$ in KM40 and TZ7 to $1.3 \%$ in TZ-5 and TZ-6. Soil nitrogen content ranged from $0.06 \%$ in TZ-7 to $0.32 \%$ in KM40. SOM ranged from $0.57 \%$ in KM40 to $4.90 \%$ in TZ-8 (Table 1).

Table 1. $\mathrm{pH}$, electrical conductivity, total carbon content $(\mathrm{C})$, total nitrogen content $(\mathrm{N})$, and soil organic matter (SOM) of AT-12 samples. Means \pm standard errors were shown for TC, TN, and SOM.

\begin{tabular}{|c|c|c|c|c|c|}
\hline AT-12 site & $\mathrm{pH}$ & $\begin{array}{l}\text { Conductivity } \\
(\mathrm{mS} / \mathrm{cm})\end{array}$ & $\begin{array}{l}\mathrm{C} \\
(\%)\end{array}$ & $\begin{array}{l}\mathrm{N} \\
(\%)\end{array}$ & $\begin{array}{l}\text { SOM } \\
(\%)\end{array}$ \\
\hline $\begin{array}{c}\text { KM40 } \\
\text { MES }\end{array}$ & 7.97 & 22.3002 & $0.12 \pm 0.02$ & $0.32 \pm 0.01$ & $0.57 \pm 0.05$ \\
\hline $\begin{array}{l}\text { PONR } \\
\text { Yungav }\end{array}$ & \multicolumn{5}{|c|}{ Not measured } \\
\hline $\mathrm{TZ}-4$ & 9.07 & 0.0346 & $0.33 \pm 0.01$ & $0.08 \pm 0.01$ & $1.50 \pm 0.09$ \\
\hline TZ-5 & 9.36 & 0.2149 & $1.36 \pm 0.23$ & $0.07 \pm 0.01$ & $1.27 \pm 0.03$ \\
\hline TZ-6 & 8.72 & 4.2845 & $1.15 \pm 0.11$ & $0.09 \pm 0.02$ & $1.23 \pm 0.03$ \\
\hline TZ-7 & 9.12 & 0.0321 & $0.10 \pm 0.01$ & $0.06 \pm 0.01$ & $1.57 \pm 0.03$ \\
\hline TZ-8 & 8.74 & 0.0410 & $0.56 \pm 0.04$ & $0.14 \pm 0.01$ & $4.90 \pm 0.13$ \\
\hline
\end{tabular}




\begin{tabular}{llllll} 
TZ-9 & 9.23 & 0.0794 & $0.77 \pm 0.02$ & $0.14 \pm 0.02$ & $3.57 \pm 0.05$ \\
\hline
\end{tabular}

X-ray diffraction (XRD) results showed significant amounts of quartz, albite, microcline, gypsum, anhydrite, and chloride among all AT-12 sample sites (Figure 2a) (Harris et al. 2016). AT-17 sites were similarly characterized by quartz, albite, and microcline. However hydrated minerals, brushite and gypsum, took over a significant percentage in the two post-rainfall hyperarid sites - PONR and Yungay. (Figure 2b \& Figure S1). Chloride minerals, primarily halite, were $\sim 3.5 \%$ in AT-12 sites but became undetectable in all AT-17 sites. The AT-17 soluble salts (i.e., chloride, nitrate, and sulfate) remained at about the same level as AT-12 in the sediments of the transition zone. However, soluble salts in AT-17 reduced remarkably in the hyperarid sites after heavy rainfalls compared to AT-12 samples (Figure 2 \& Table S1).

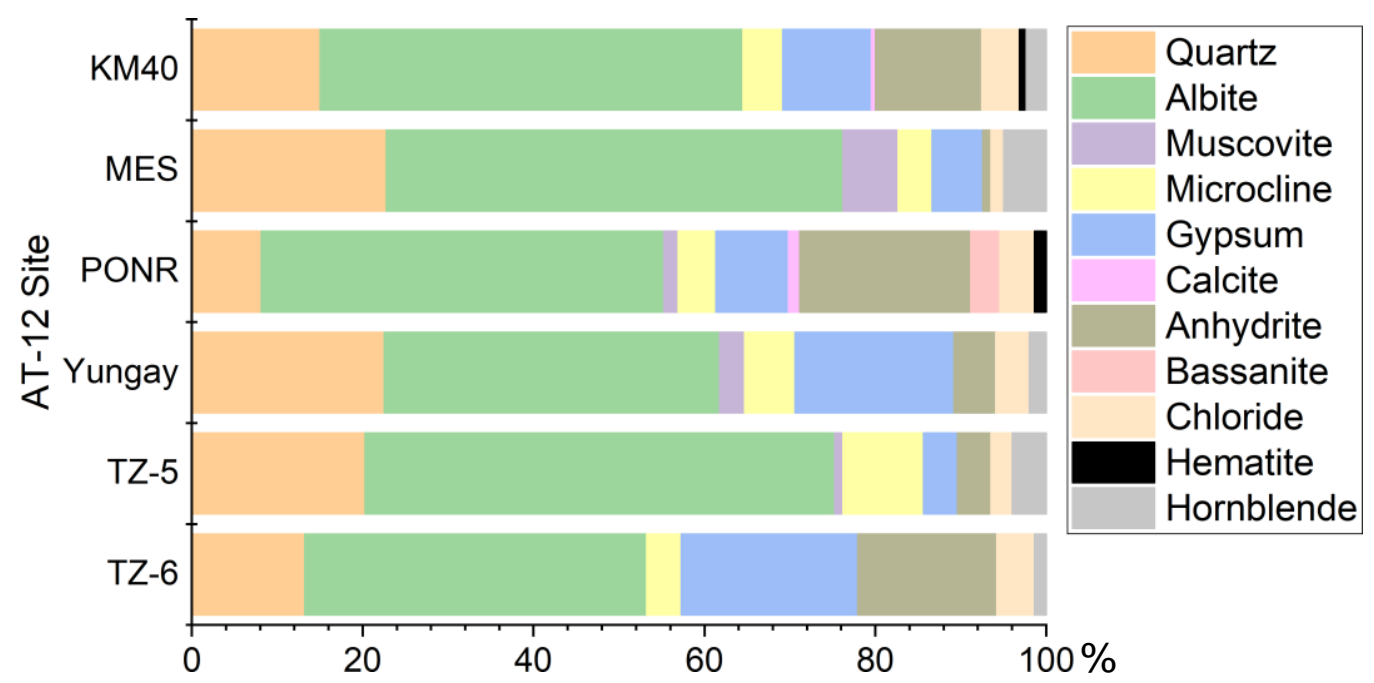

(a)

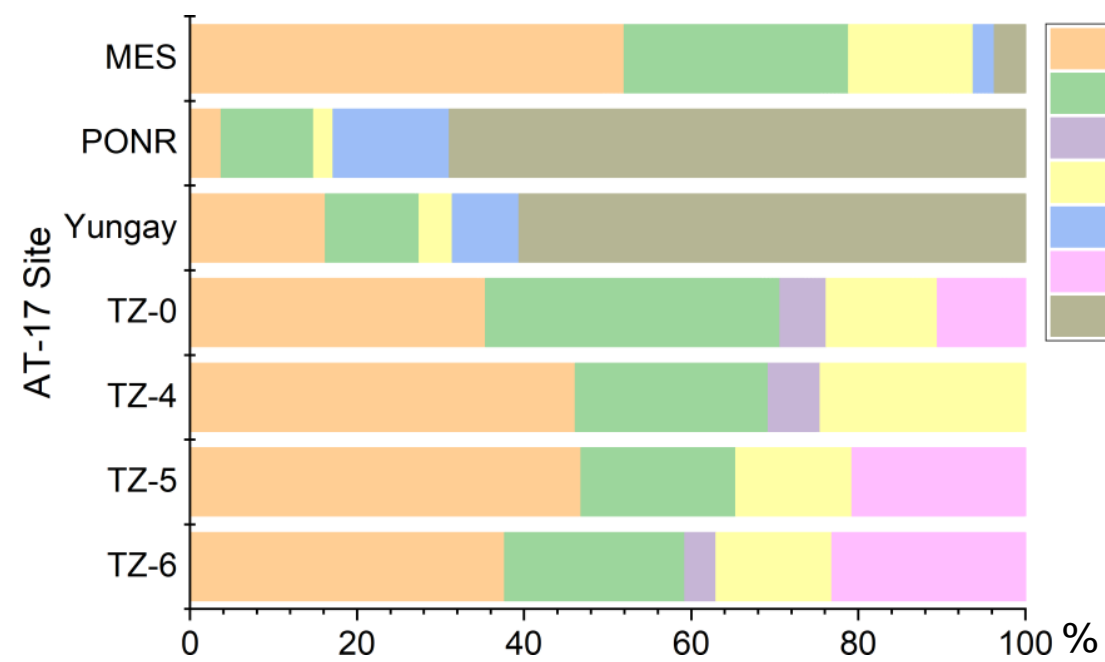

(b)

\section{Quartz Albite Muscovite Microcline Gypsum Calcite Brushite}

Figure 2. Percentages of different minerals from (a) 2012 and (b) 2017 determined by X-ray diffraction (XRD). 


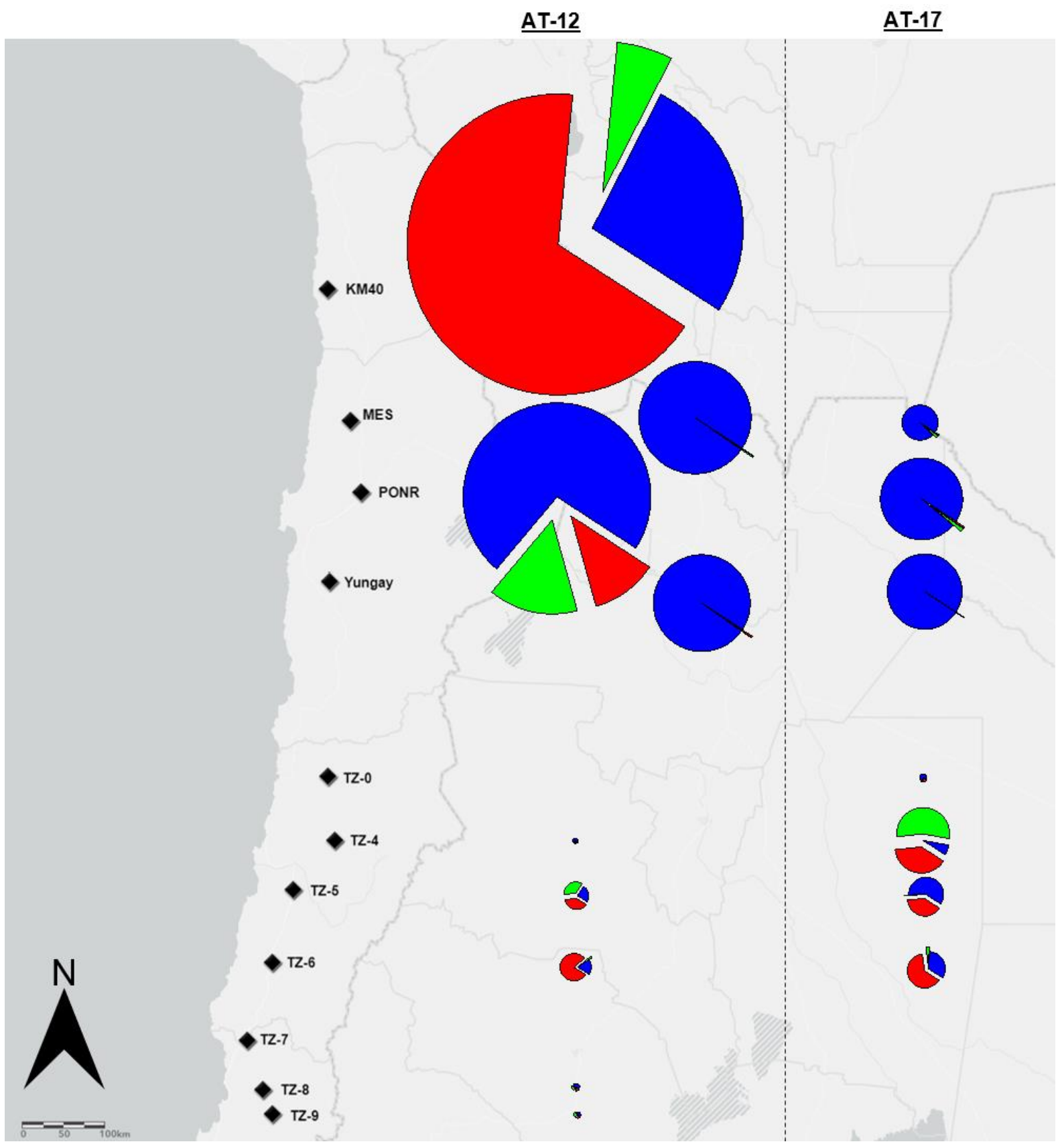

Figure 3. Soil collection sites in the Atacama Desert from 2012 and 2017, illustrating the major salt distribution of different sites. Size of pie charts represents the concentrations of soluble salts (Cl-, red; $\mathrm{NO}_{3}^{-}$, green; $\left.\mathrm{SO}_{4}{ }^{2-}, \mathrm{blue}^{2}\right)$. The areas of pie charts range from $17 \mathrm{ppm}$ to $270,000 \mathrm{ppm}$.

\subsection{Bacterial abundance and viability}

To assess the abundance and viability of Atacama bacterial communities, flow cytometry, trypan blue staining assay, and cell culture experiments were employed to Atacama soil samples. Cell counts , determined by flow cytometry and trypan blue staining, remained nearly unchanged between all the AT-12 and AT-17 bacterial communities (Figure 4 \& Table S2). Although no significant difference in total cell counts was found between the hyperarid and southern transition sites either within AT-12 or 
AT-17 samples (Figure 4 \& Table S2), the active viable bacterial colonies increased significantly toward the transition zone with higher annual precipitation (Figure 5). The viable : non-viable ratio in hyperarid soils also increased sharply from 2012 to 2017. Despite a large variation from 0.6 to 6.1 in the viable : non-viable ratios, the number of viable cells and total cells in the transition zone stayed stable (Figure 4 \& Table S2).

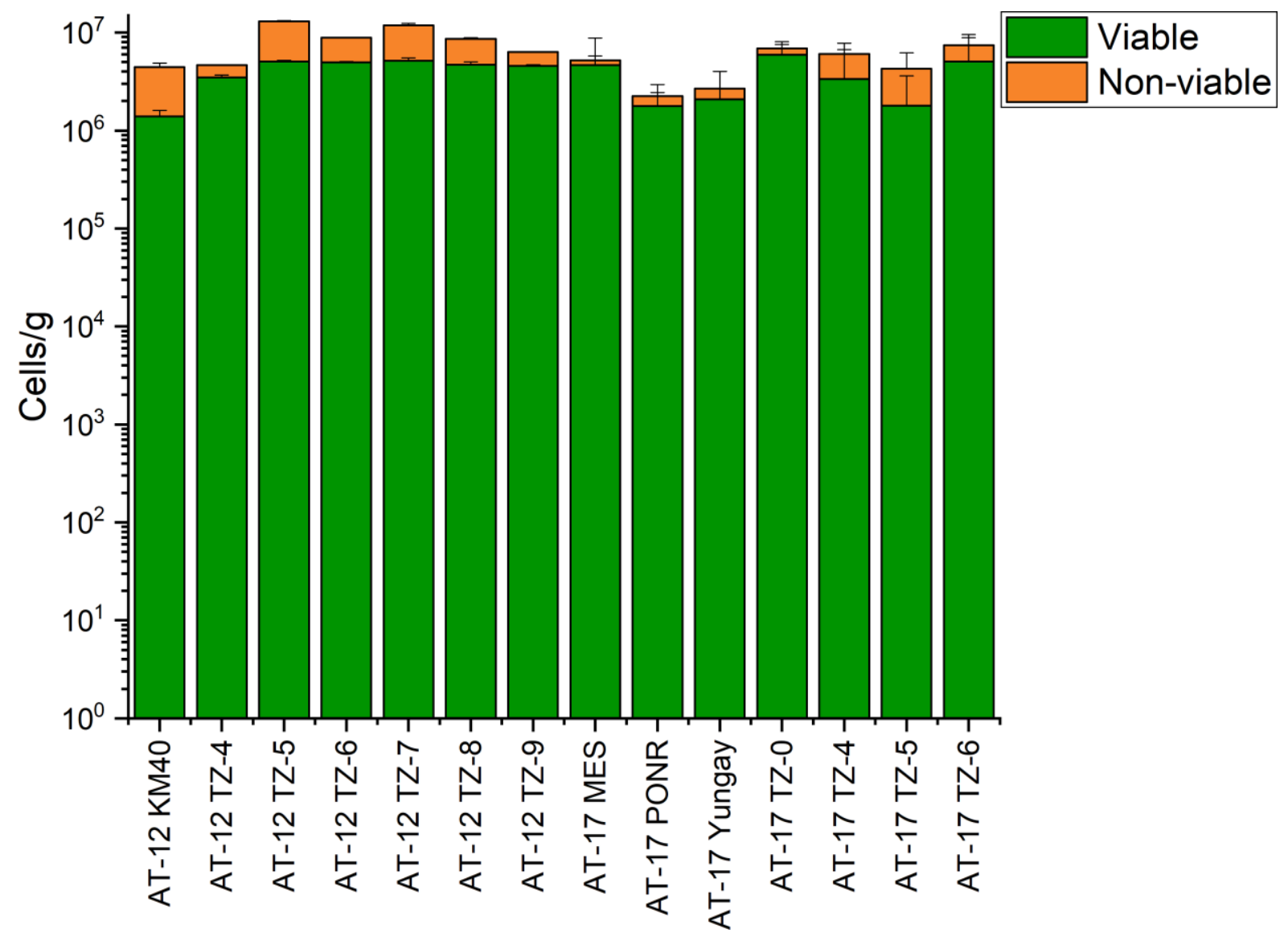

Figure 4. Accumulative bacterial cell counts per gram of soils of AT-12 samples determined by cytometric analysis and of AT-17 samples determined by trypan blue staining assay.

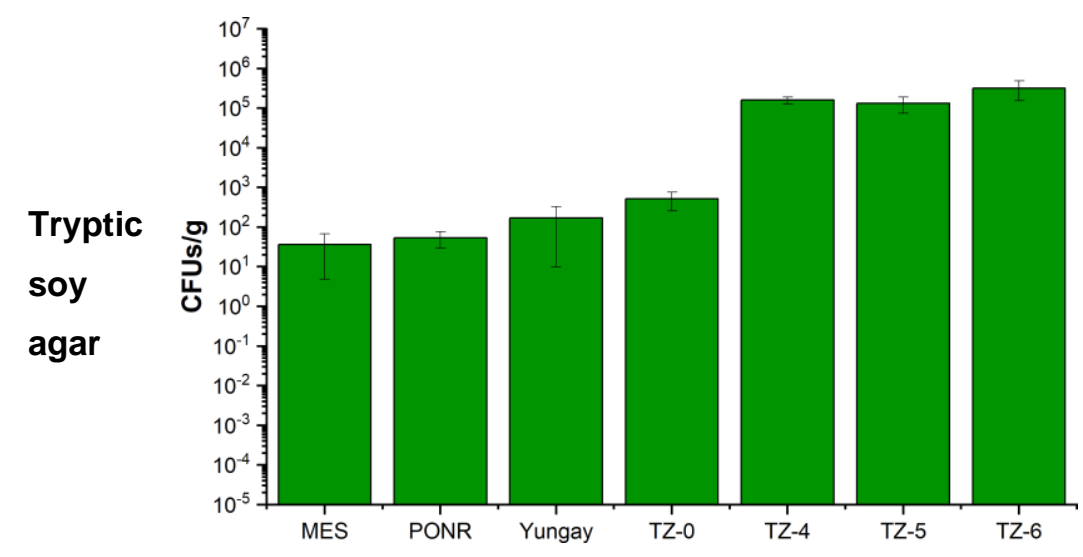



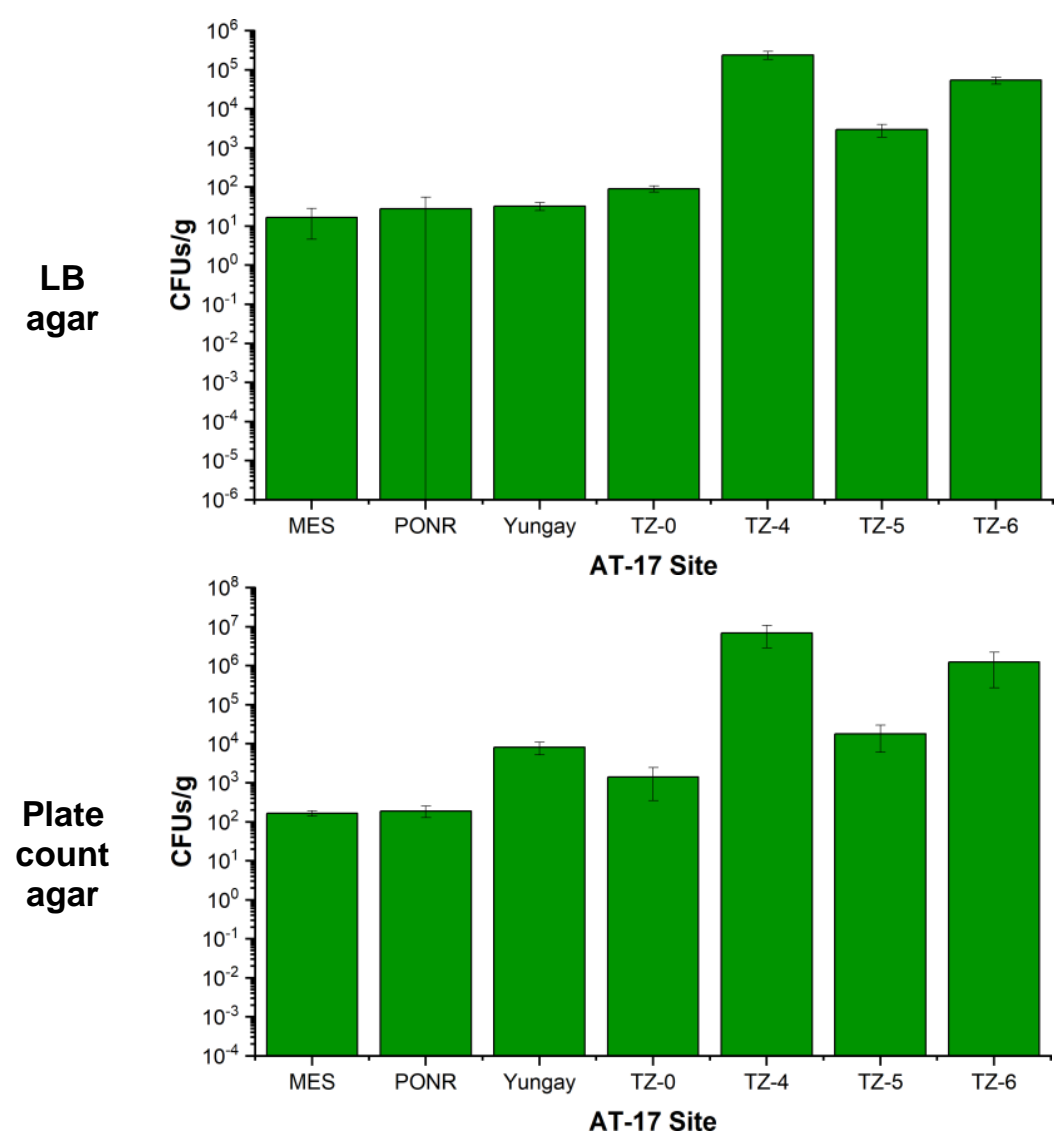

Figure 5. Viable aerobic heterotrophic colony forming units (CFUs) on tryptic soy agar, LB agar, and plate count agar plates.

Within the hyperarid core of the Atacama Desert in 2017, TOC was negatively correlated with the contents of sediment sodium and chloride (Figure 6a \& b). However, TOC was positively associated with the concentrations of the water-soluble chloride and sulfate, and the $\mathrm{HCl}$-soluble carbonate (Figure 6c, d).

\section{Annual precipitation $\leq 2 \mathrm{~mm} / \mathrm{yr}$ only}

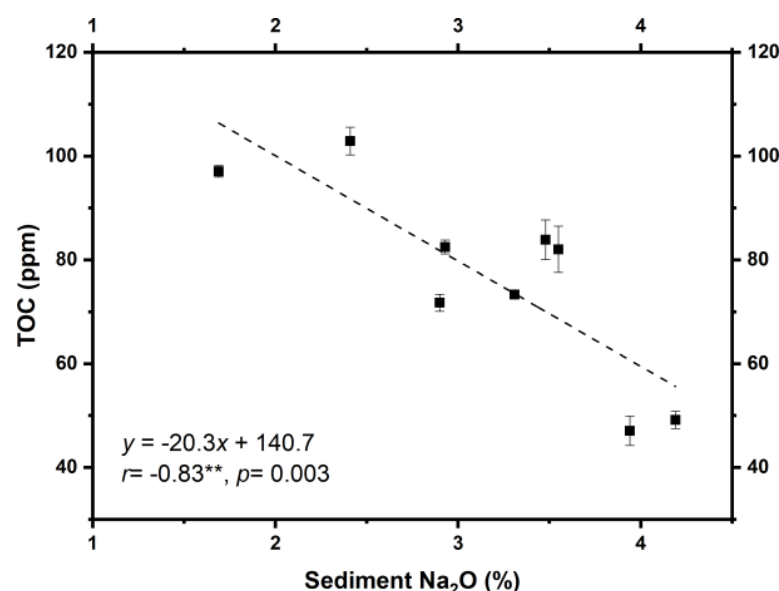

(a)

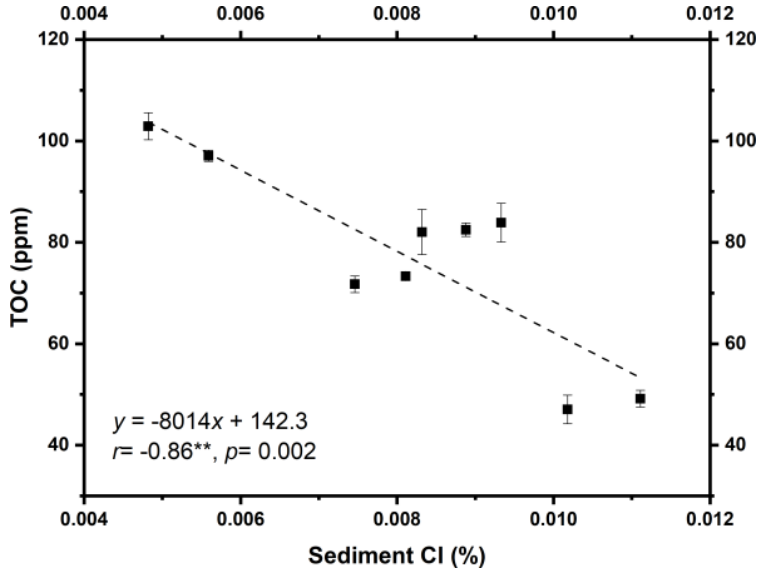

(b) 


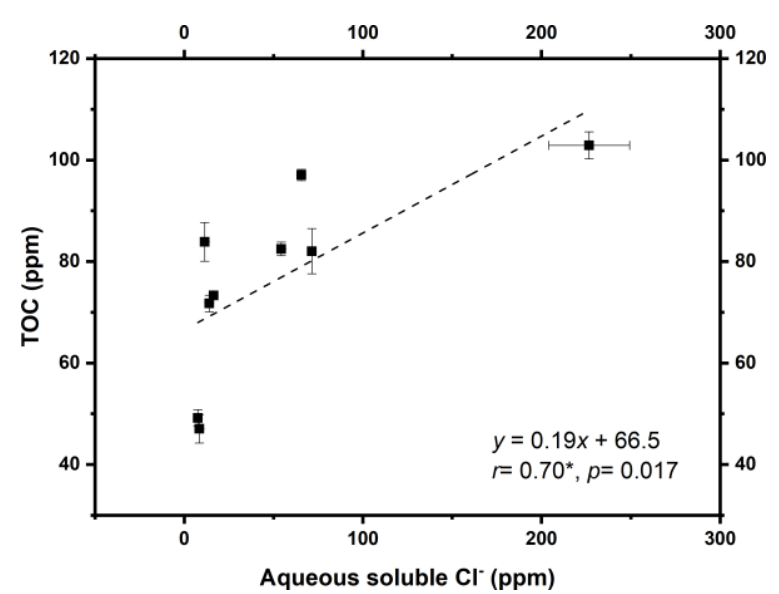

(c)

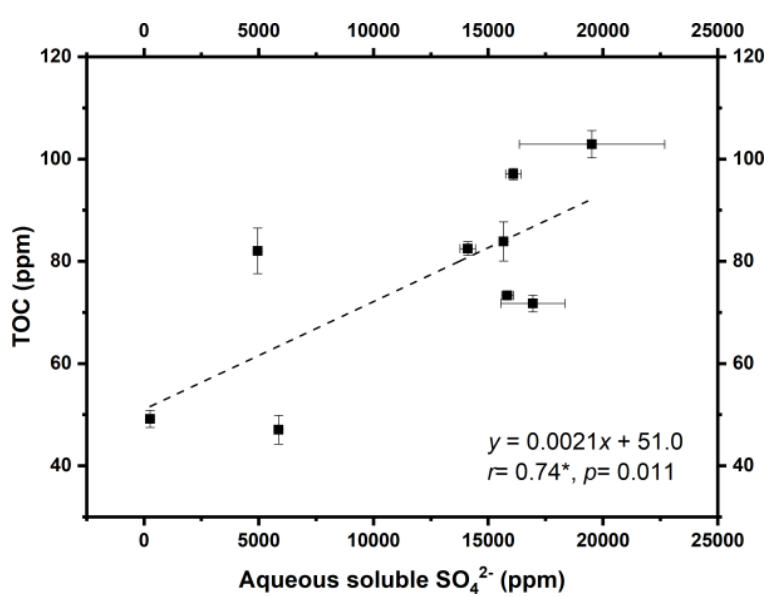

(d)

Figure 6. Plots of total organic carbon (TOC) and (a) sediment sodium, (b) sediment chloride, (c) water soluble chloride, and (d) water soluble sulfate.

Soil microbial communities show different preferences to the water volume on different agar plates (Bagaley 2006; Balestra and Misaghi 1997; Drees et al. 2006; Knief et al. 2019; Navarro-Gonzalez et al. 2003; Sieuwerts et al. 2008). Water amendment cultures (1.5, 3 and $4.5 \mathrm{~mL})$ demonstrate that transition sites were slightly less water-limited than hyperarid sites. In general, bacteria from all Atacama sampling sites benefit from increased water, but growth rate did not always increase with further water addition, especially the $1.5 \mathrm{~mL}$ and $3 \mathrm{~mL}$ amendments (Figure 7 \& Table S3 \& Table S4). On average, excessive sodium chloride and sodium carbonate amendments decreased cell counts; sodium sulfate and sodium acetate had no effect; and sodium L-lactate increased cell counts. Sites with higher annual precipitation generally had a higher tolerance or higher preference to the amendments with these salts, except for sodium carbonate (Figure 7 \& Table S5).

\section{Water amendment}

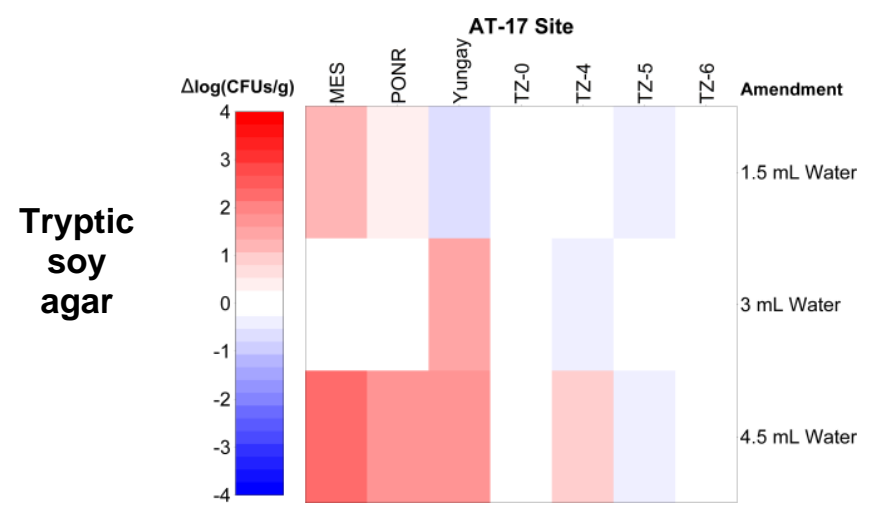

\section{Salt amendment}

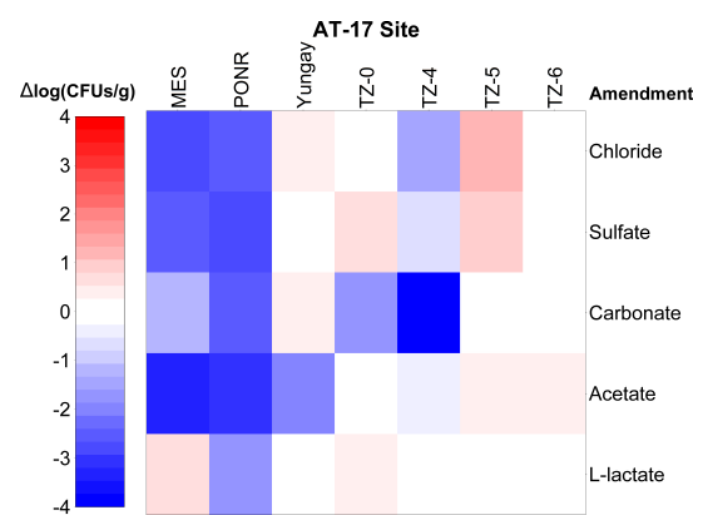




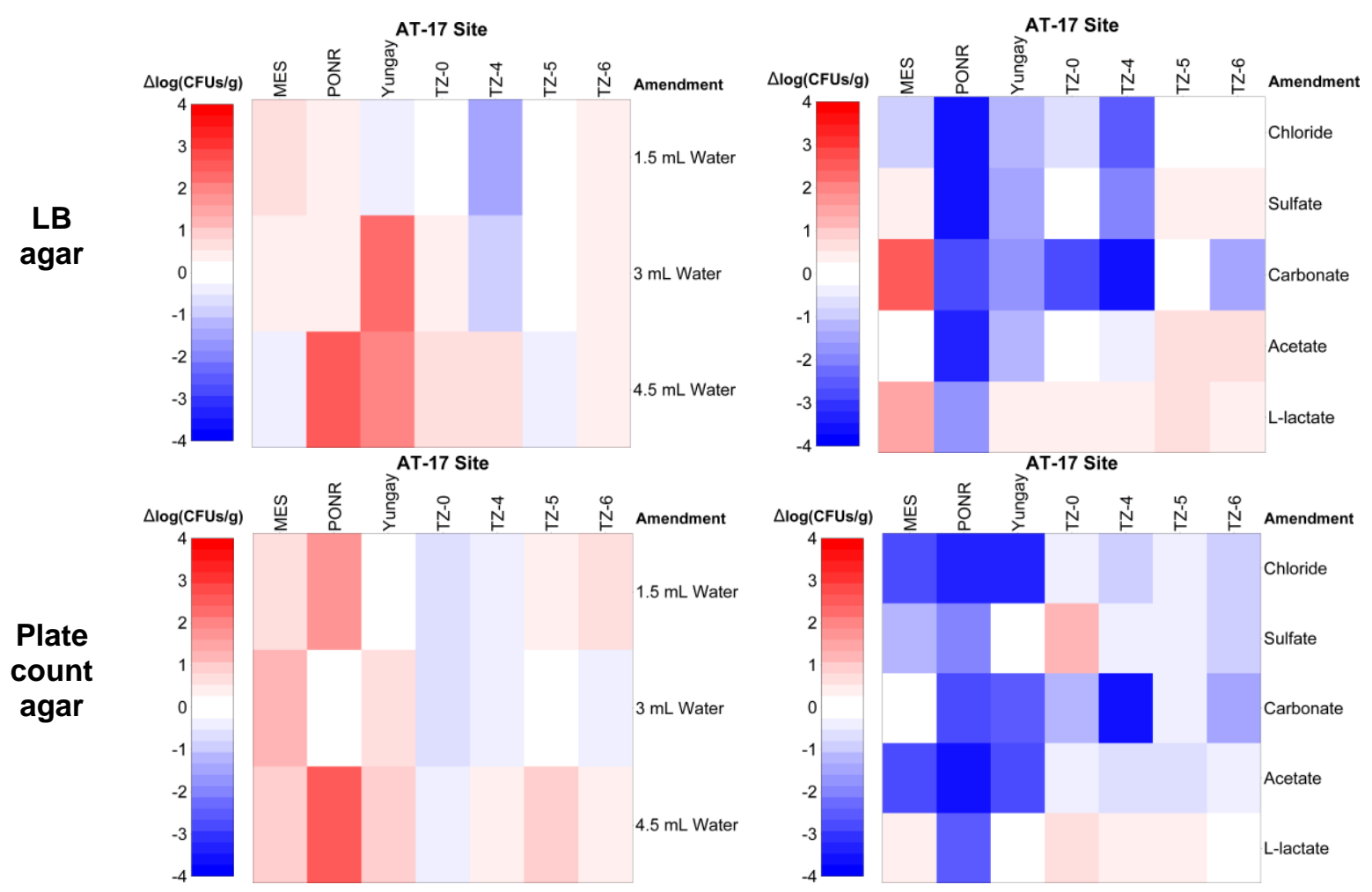

Figure 7. Heatmaps of relative growth rate of bacteria on tryptic soy agar, LB agar, and plate count agar plates, illustrating the change in the order of magnitude of CFUs with water and salt amendments (red, positive values; blue, negative values). Left panel, all values in water amendment cultivations are scaled by logarithmic transformation and normalized as the difference from the plates without amendments; right panel, all values in salt amendment cultivations are scaled by logarithmic transformation and normalized as the difference from the plates with 4.5-mL water amendments.

\subsection{Microbial community diversity and molecular characterizations}

Within the AT-12 samples, KM40 and Yungay had remarkably low Shannon's diversity (4.55 and 4.66 respectively) than other sites which were all above 6.96. For AT-17, the order of diversity was MES, TZ4, TZ-0, TZ-5, TZ-6 (Table 2). The microbial diversity of the AT-17 hyperarid site MES was higher than the two AT-12 hyperarid sites, KM40 and AT-12 Yungay (Figure 8 \& Figure S2). However, the diversity of all arid sites of AT-17 were generally lower than all arid sites of AT-12 except for AT-12 TZ-6 (Table 2 \& Figure 8 \& Figure S2). The biodiversity at site TZ-6 was significantly lower than other transition sites in 2012, but was the highest among all sites in 2017.

Soils within the AT-12 hyperarid KM40 and Yungay were dominated by Aquificae (73.05\%) and Deinococcus-Thermus (21.02\%), while soils within the AT-12 arid southern desert were dominated by Actinobacteria (42.28\%), Proteobacteria (15.74\%), and Acidobacteria (10.36\%). The bacterial phyla dominated soils within the AT-17 hyperarid MES were Actinobacteria (66.27\%), Proteobacteria (12.65\%), and Chloroflexi (11.83\%); and those dominated soils within AT-17 arid southern desert were Actinobacteria (50.42\%), Chloroflexi (16.13\%), and Proteobacteria (11.48\%) (Figure 9). 
ANCOM results suggested that genus Streptomyces (Actinobacteria) was significantly different $(W=703$, $p<0.05)$ between the hyperarid core and transition zone. Genera Thermus (Deinococcus-Thermus), Thermocrinis (Aquificae), and uncultured AKIW781 (Chloroflexi) were significantly different $(W=1050$, 1050, and 952, respectively, $p<0.05$ ) between the pre-rainfall 2012 and post-rainfall 2017. Characteristic known genera in the hyperarid core were Thermus (Deinococcus-Thermus), Thermocrinis (Aquificae), Escherichia-Shigella (Gammaproteobacteria), and Pseudomonas (Gammaproteobacteria), while characteristic known genera in the transition zone were Rubrobacter (Actinobacteria), uncultured Gammaproteobacteria, Bacillus (Firmicutes), and Solirubrobacter (Actinobacteria).

Table 2. Shannon diversity, Faith's phylogenetic diversity (PD), species evenness, and observed OTU richness indices of AT-12 and AT-17 samples.

\begin{tabular}{ccccc}
\hline Site & Shannon & Faith's & & Observed \\
& (binary log) & PD & & OTUs \\
\hline AT12-K (KM40) & 4.55 & 7.7 & 0.626 & 154 \\
AT12-Y (Yungay) & 4.66 & 12.7 & 0.629 & 170 \\
AT12-T4 (TZ-4) & 8.84 & 37.4 & 0.941 & 672 \\
AT12-T5 (TZ-5) & 8.83 & 44.3 & 0.936 & 693 \\
AT12-T6 (TZ-6) & 6.96 & 22.0 & 0.845 & 302 \\
AT12-T7 (TZ-7) & 9.37 & 49.4 & 0.964 & 844 \\
AT12-T8 (TZ-8) & 9.05 & 48.8 & 0.943 & 771 \\
AT12-T9 (TZ-9) & 9.47 & 56.0 & 0.970 & 865 \\
\hline AT17-M1 (MES pit 1) & 6.63 & 19.3 & 0.857 & 213 \\
AT17-M2 (MES pit 2) & 5.57 & 11.9 & 0.802 & 123 \\
AT17-M3 (MES pit 3) & 5.55 & 13.9 & 0.800 & 123 \\
AT17-T01 (TZ-0 pit 1) & 7.27 & 24.6 & 0.868 & 332 \\
AT17-T02 (TZ-0 pit 2) & 6.80 & 20.4 & 0.841 & 270 \\
AT17-T41 (TZ-4 pit 1) & 6.86 & 22.5 & 0.862 & 250 \\
AT17-T42 (TZ-4 pit 2) & 6.87 & 22.7 & 0.857 & 260 \\
AT17-T43 (TZ-4 pit 3) & 6.50 & 20.9 & 0.837 & 217 \\
AT17-T51 (TZ-5 pit 1) & 8.01 & 35.0 & 0.917 & 427 \\
AT17-T52 (TZ-5 pit 2) & 7.79 & 37.8 & 0.871 & 491 \\
AT17-T53 (TZ-5 pit 3) & 7.41 & 27.9 & 0.884 & 334 \\
AT17-T61 (TZ-6 pit 1) & 7.80 & 32.1 & 0.893 & 427 \\
AT17-T62 (TZ-6 pit 2) & 7.95 & 31.5 & 0.916 & 411 \\
AT17-T63 (TZ-6 pit 3) & 8.22 & 32.6 & 0.935 & 443 \\
\hline
\end{tabular}




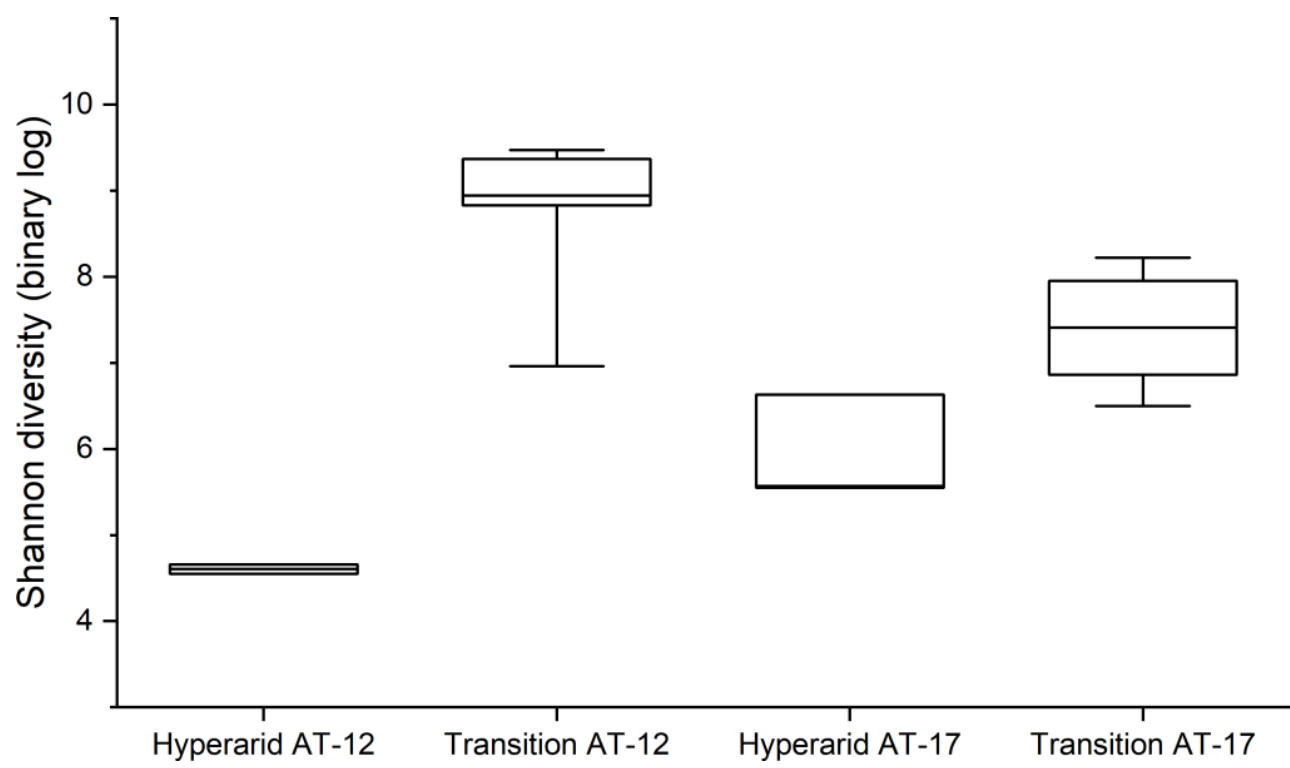

Figure 8. Shannon diversity indices of hyperarid and transition sites from 2012 and 2017.

Site

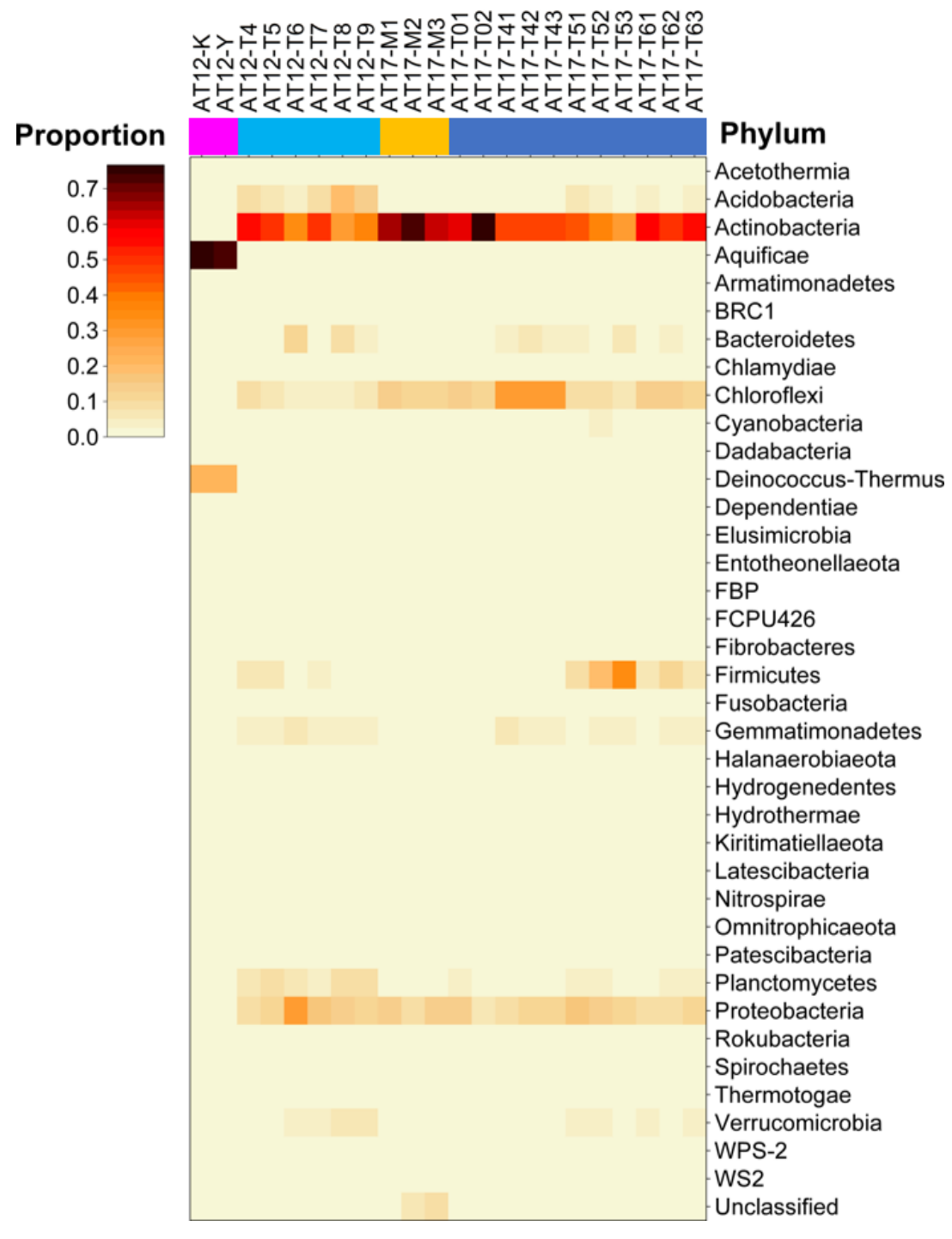


Figure 9. The heatmap illustrating phylum level microbial composition in soils of the Atacama Desert from sequencing data. (Pink, hyperarid AT-12, KM40 and Yungay; light blue, transition AT-12, TZ-4 to TZ-9; yellow, hyperarid AT-17, 3 pits in MES; dark blue, transition AT-17, 2 pits in TZ-0 and 3 pits in TZ-4 to TZ-6)

\subsection{Ordination analyses of study sites}

Hierarchical clustering indicated that the least diverse AT-12 transition site, TZ-6, had similar microbial compositions to the most humid transition sites, TZ-8 and TZ-9. AT-12 TZ-4, TZ-5, and TZ-7 were closely related to each other, and most similar to AT-17 TZ-6 (Figure 10a). Three pits within each individual AT-17 site generally had similarity more than $85 \%$, except for the $60 \%$ similarity in site TZ5. The hyperarid microbiome in AT-17 MES was most similar to the most northern transition site AT17 TZ-0. The similarity of microbial compositions in the transition zone between 2012 and 2017 was 6075\%, while in the hyperarid core, the similarity became 0\% between 2012 and 2017 (Figure 10a). Without the confounding sites AT-12 KM40 and AT-12 Yungay, principal coordinate analysis (PCoA) displayed a consistent trend with hierarchical clustering approach. In more detail, PCoA separated the AT-12 transition sites, AT-17 transition sites, and AT-17 hyperarid sites more clearly; the hyperarid AT-17 MES microbial compositions were more similar to both of the northernmost and the southernmost AT17 transition sites, i.e., TZ-0 and TZ-6; and AT-17 TZ-4 to TZ-6 sites were positioned close to AT-12 TZ4 to TZ-9 in terms of the PCo1 axis (Figure 10b).

Soil microbial communities from different sites showed variable combinations of measured biogeochemical factors. According to the localization in quadrants of principal component coordinates, AT-12 KM40 and AT-17 TZ-5 were characterized by high N content and soluble chloride; AT-17 samples PONR, Yungay, and TZ-4 were characterized by high electrical conductivity, soluble sulfate, and C content; AT-12 TZ-4 and AT-17 samples MES, TZ-0, and TZ-6 were characterized by high elevation and microbial viability; and the other AT-12 transition sites were characterized by high $\mathrm{pH}$ and SOM (Figure 10c). 


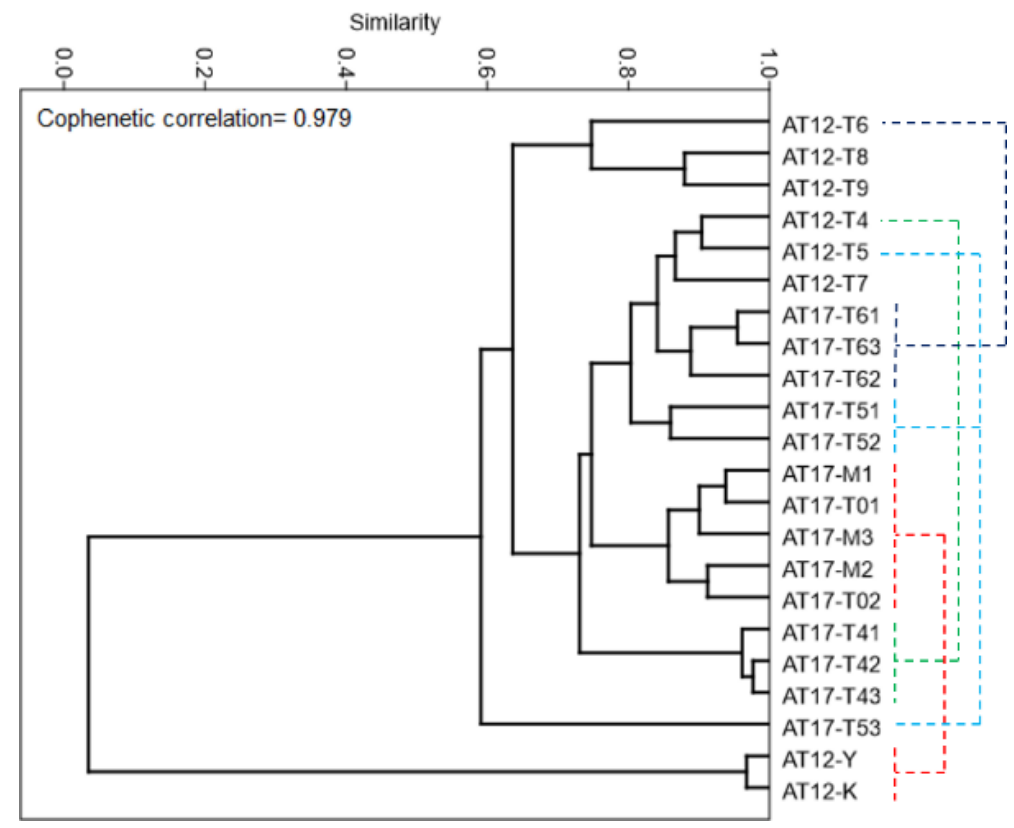

(a)

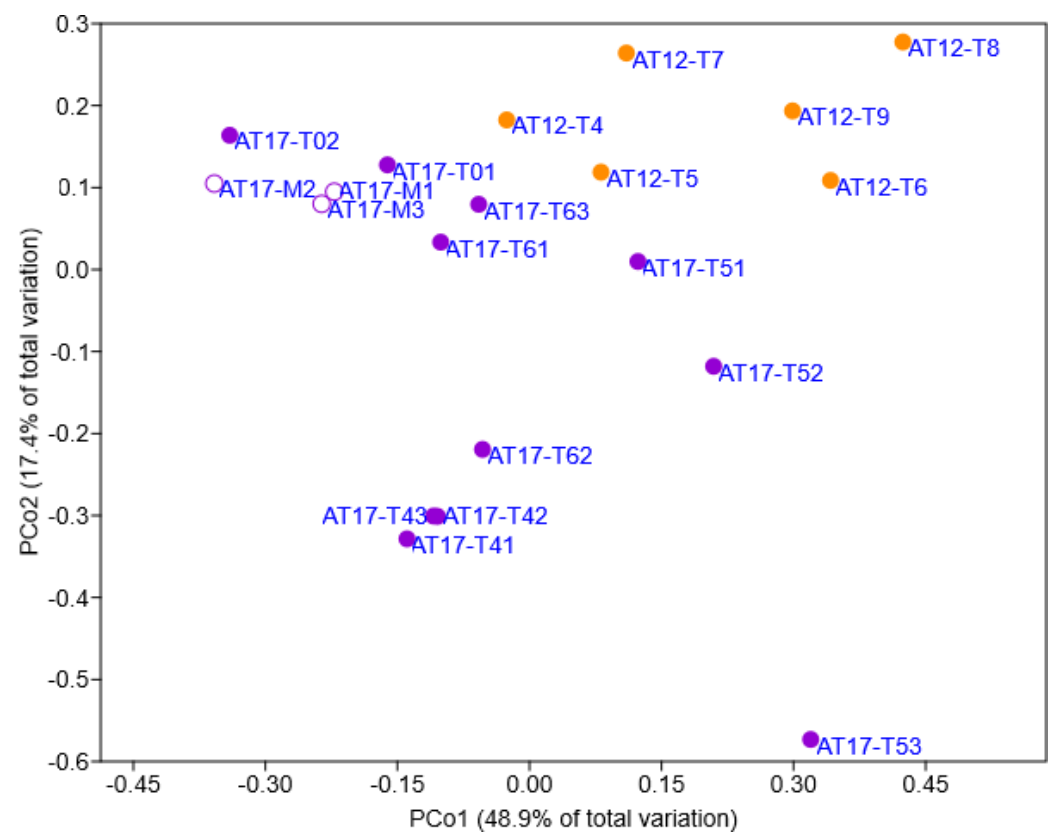

(b) 


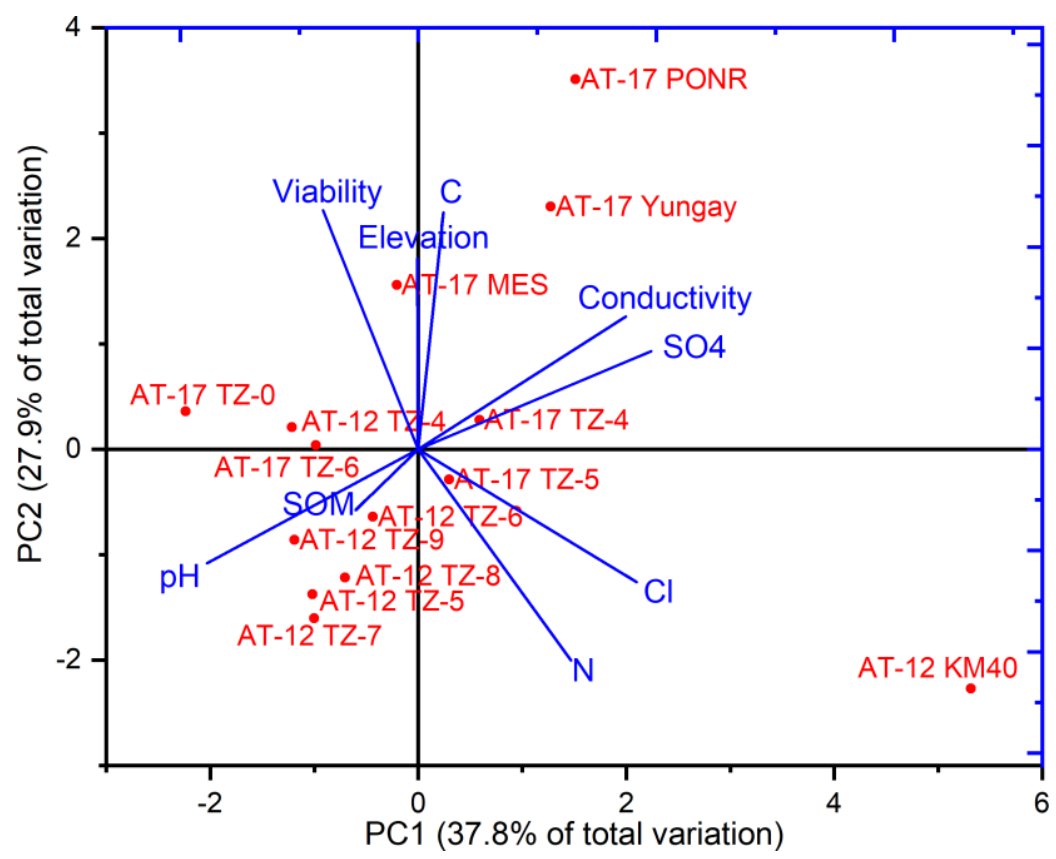

(c)

Figure 10. (a) Hierarchical clustering (Bray-Curtis distance matrix and unweighted pair group method with arithmetic mean algorithm) of microbial compositions at the species level in AT-12 and AT-17 sites (red dash line, hyperarid; green dash line, TZ-4; light blue dash line, TZ-5; dark blue, TZ-6); (b) principal coordinate analysis (PCoA) of microbial compositions at the species level in AT-12 and AT-17 sites (orange dot, arid AT-12; purple circle, hyperarid AT-17; purple dot, arid AT-17); (c) principal component analysis (PCA) of fundamental physicochemical properties in AT-12 and AT-17 sites. Abbreviations in (a) and (b) as in Table 2.

\subsection{Pathway and network analyses}

Metabolism structure of hyperarid AT-17 microbiomes was overall more similar to transition sites than hyperarid AT-12. Compared to transition sites, hyperarid AT-17 had less proportions of amine and polyamine biosynthesis, aminoacyl-tRNA charging, detoxification, glycan biosynthesis and degradation, nucleoside and nucleotide degradation, polymeric compound degradation, and secondary metabolite degradation. Hyperarid AT-12 microbiomes were generally the lowest in all metabolisms, but the highest in $\mathrm{C} 1$ compound utilization and assimilation, cell structure biosynthesis, metabolic regulator biosynthesis, nucleic acid processing, nucleoside and nucleotide biosynthesis, pentose phosphate pathways, photosynthesis, and secondary metabolite biosynthesis (Figure 11).

Various adaptation pathways coupled with environmental stress reactions and salt/ small organic consumptions were predicted based on feature sequences (Figure 12). Transition AT-12 and AT-17 sites had similar proportions of these pathways. Hyperarid AT-17 sites had slightly lower proportions of pathways coupled with stress reactions, but higher proportions of nitrate and sulfate utilization pathways. Hyperarid AT-12 sites had the lowest proportions of all these targeted pathways (Table 3). Here, the co-occurrences of bacterial OTUs that are statistically significant in Spearman's rank 
correlation matrix are used to construct the edges of network (Barberan et al. 2012). The network analysis results revealed that the microbial OTUs of transition sites had more edges, higher edge to node ratios, and higher degrees (edges connected to a node) than hyperarid sites (Figure 13 \& Table 4), indicating a more densely connected community in the transition zone. OTUs from the hyperarid core showed a higher modularity ( $>0.4$ indicates a modular structure) and an unconnected "island effect" (Neilson et al. 2017; Newman 2003). However within each hyperarid "island", the network was tighter, according to its shorter average path length and lower betweenness centralization score, than the whole transition community (Table 4).

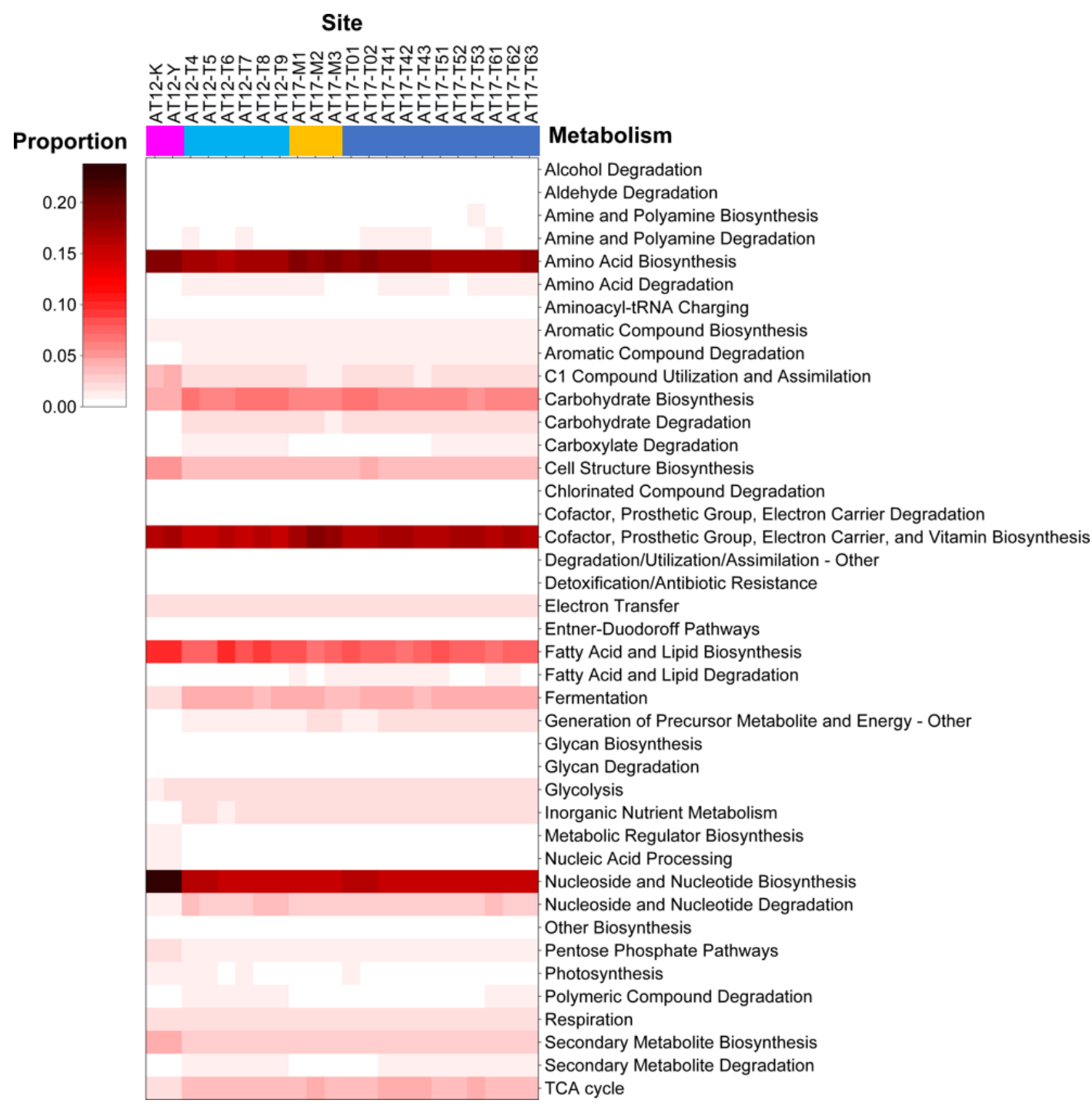

Figure 11. Microbial metabolisms presented as the secondary superclass in MetaCyc classification system. (Pink, hyperarid AT-12, KM40 and Yungay; light blue, transition AT-12, TZ-4 to TZ-9; yellow, hyperarid AT-17, 3 pits in MES; dark blue, transition AT-17, 2 pits in TZ-0 and 3 pits in TZ-4 to TZ-6) 


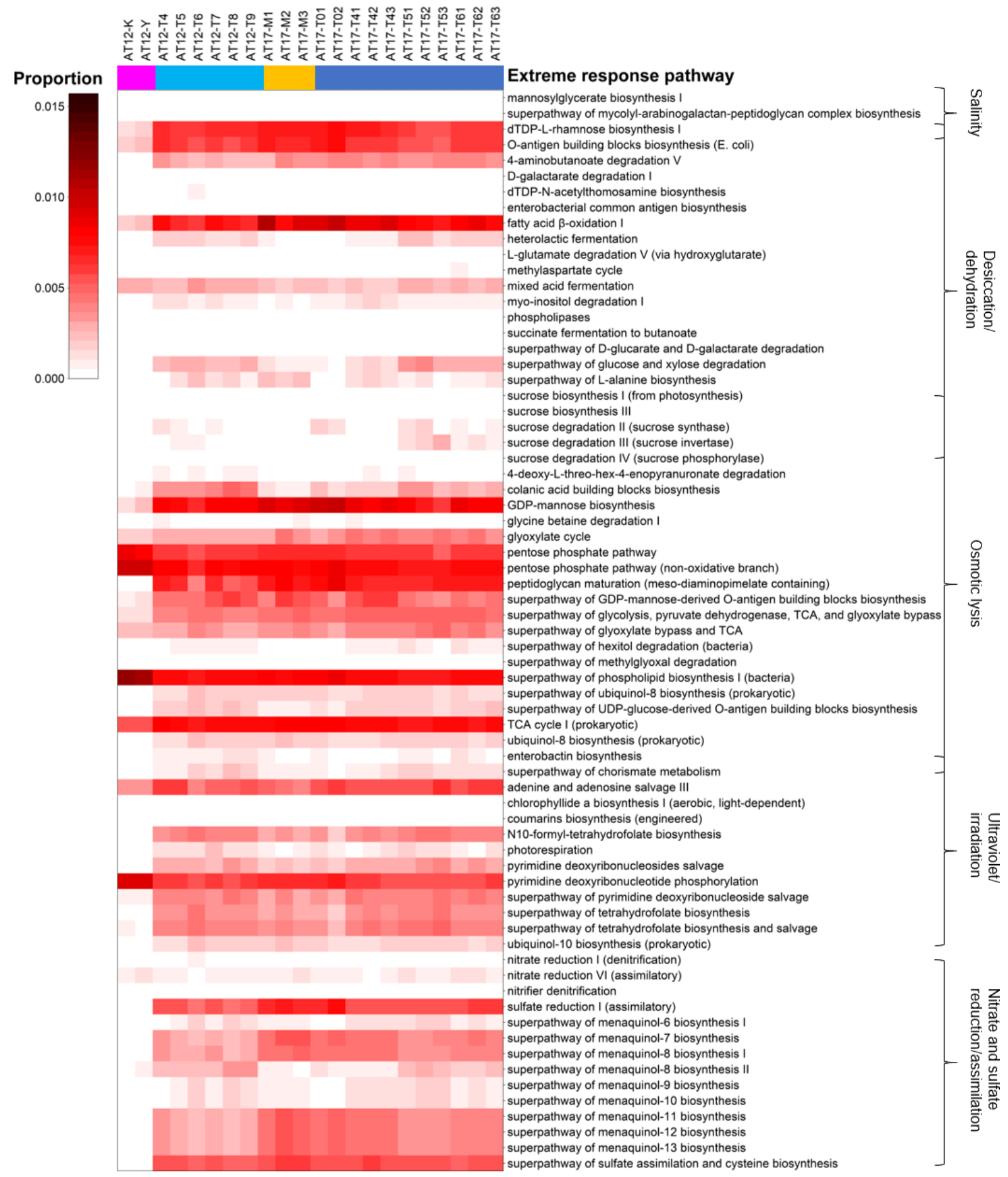

Figure 12. Microbial functional pathways that are associated with stressor responses from Atacama soil samples across a precipitation gradient collected in 2012 and 2017. (Pink, hyperarid AT-12, KM40 and Yungay; light blue, transition AT-12, TZ-4 to TZ-9; yellow, hyperarid AT-17, 3 pits in MES; dark blue, transition AT-17, 2 pits in TZ-0 and 3 pits in TZ-4 to TZ-6)

Table 3. Percentages of metabolic pathways related to stressor responses from Atacama soils in the hyperarid core and the transition zone sampled in 2012 and 2017. 


\begin{tabular}{lrrrc}
\hline Stressor response pathways (\%) & $\begin{array}{c}\text { Hyperarid } \\
\text { AT-12 }\end{array}$ & $\begin{array}{c}\text { Transition } \\
\text { AT-12 }\end{array}$ & $\begin{array}{l}\text { Hyperarid } \\
\text { AT-17 }\end{array}$ & $\begin{array}{l}\text { Transition } \\
\text { AT-17 }\end{array}$ \\
\hline Desiccation/ dehydration & 0.96 & 3.32 & 3.35 & 3.45 \\
Ultraviolet/ irradiation & 1.60 & 3.52 & 3.01 & 3.39 \\
Salinity & 0.36 & 1.25 & 1.40 & 1.25 \\
Simple organic molecule metabolisms & 6.77 & 9.26 & 8.37 & 9.18 \\
Nitrate reduction/ assimilation & 0.29 & 2.17 & 2.79 & 2.62 \\
Sulfate reduction/ assimilation & 0.05 & 1.03 & 1.25 & 1.15 \\
Osmotic lysis & 4.48 & 7.28 & 7.19 & 7.38 \\
\hline
\end{tabular}

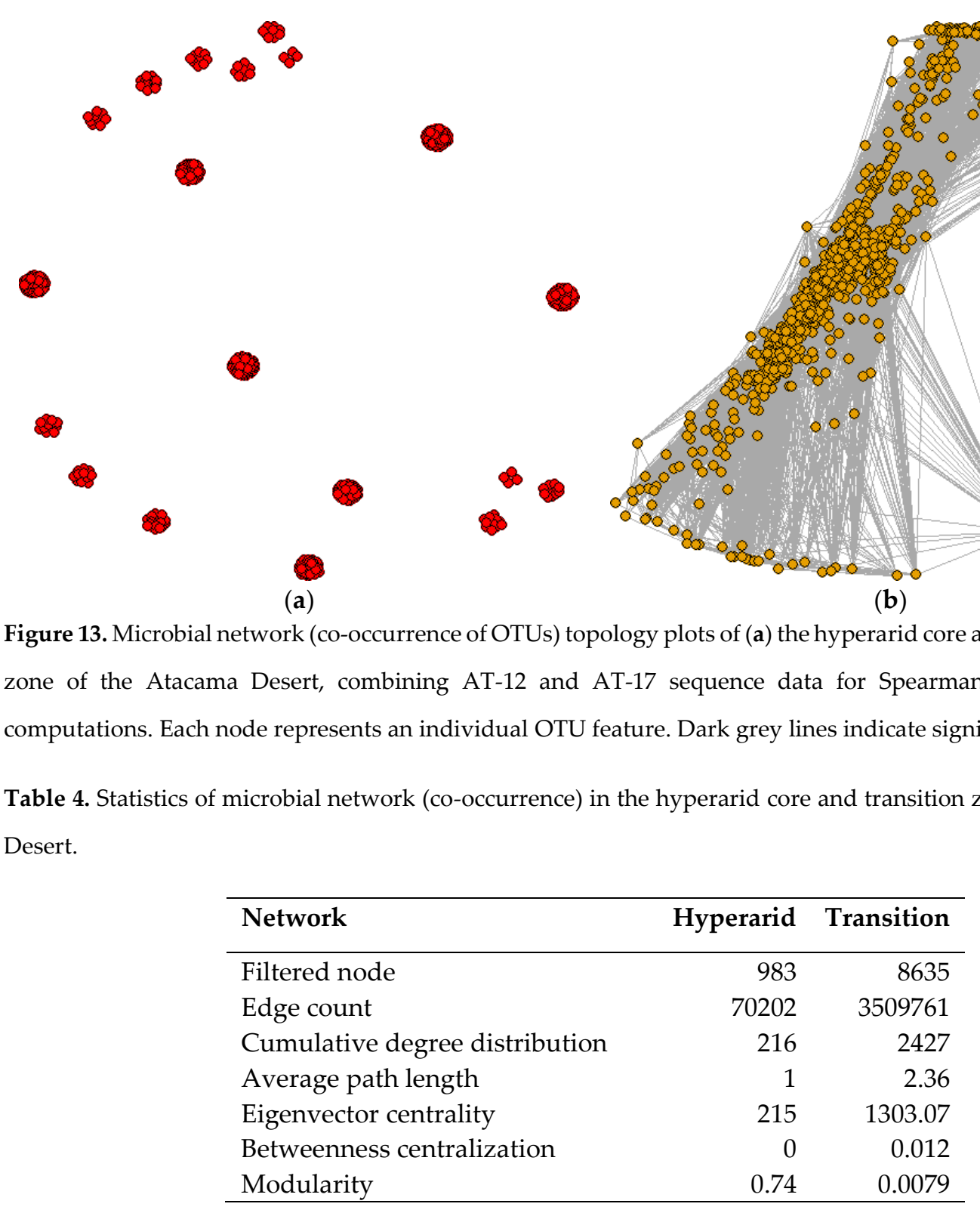

\section{Discussion}

4.1. Effects of water and salt regulations on microbial growth 
In the Atacama Desert, gypsum, halite, anhydrite, atmospherically derived nitrate, and other inorganic salts accumulate in the soil (Ericksen 1983), leading to soil oxidation, variable electrical conductivity, and abiotic chemical decomposition of soil organic matters (SOM) (Ewing et al. 2007; Gómez-Silva et al. 2008; Quinn et al. 2007). The accretion of inorganic salts is a rare phenomenon that occurs only under extremely arid conditions and makes the Atacama Desert an ideal environment to examine the influence of extreme aridity on subsurface terrestrial or even Martian microbial "life" (FernandezMartinez et al. 2019; Shen et al. 2019; Warren-Rhodes et al. 2019). The Atacama Desert exhibited considerable variation in soil geochemistry along the $\sim 1,000 \mathrm{~km}$ sampled transect, and our results indicated that while annual precipitation is a limiting factor for soil microbial communities, other aspects of soil chemistry also influenced microbial life. As conditions become more arid in the northern reaches of the desert, salts, ores, and metals accumulate at the surface and at shallow depths. Increased precipitation in the southern desert inhibits this accumulation as more soluble compounds are transported deeper into the subsurface (Ericksen 1983).

We found that the viable and total cell counts were not significantly different between hyperarid and transition sites in terms of the order of magnitude (Figure $4 \&$ Table S2). However, microbial viability in Atacama soils was variable, with the lowest in the northern hyperarid soils in 2012 (Figure 4 \& Table S2). Across the AT-12 sampling transect, the percentage of viable cells ranged from $31 \%$ (KM40) to $75 \%$ (TZ-4), much lower than typical soils with viable cell counts which usually surpass $90 \%$ (Janssen et al. 2002; Parinkina 1973), yet within the range of viability in soils associated with increased selective pressures (e.g., desiccated mineral soils, high UV radiation, low nutrient, and water availability) (Hansen et al. 2007; Saul-Tcherkas and Steinberger 2011; Shi et al. 1997). The harsh environmental conditions associated with hyperaridity, a reduced environment with low water and nutrient availability, represent the most likely cause of this difference in microbial viability between the two regions. However, in AT-17 sampling sites, the microbial viability decreased from northern hyperarid soils, up to $89 \%$, to southern transition soils, down to 39\% (Figure 10c \& Table S2). This increased viability in the hyperarid region could be a consequence of the loss of non-viable cells as an additional implication of the rainfall leaching effects (Artz et al. 2005; Pruett et al. 1980).

The microbial cultivation experiments (without any amendments) demonstrated that the CFUs from AT-17 samples increase up to 4 orders of magnitude from the hyperarid sites to transition sites (Figure 5 \& Table S3). The reasons for the difference between viable cell counts and culturable microbial colony numbers might be that 1) more unculturable species live in the hyperarid core (Ma et al. 2009; WarrenRhodes et al. 2019), and that 2) most of the hyperarid microbiomes are metabolically inactive (Barros et al. 2008; Jones 1971; Navarro-Gonzalez et al. 2003; Schulze-Makuch et al. 2018; Zahran 1997). Since the 
Actinobacteria-dominated microbial community structure does not alter much between the hyperarid AT-17 and transition AT-17 sites (Figure 9 \& Figure 10a, b), the latter hypothesis might play a more important role in the culturable CFUs.

The agar cultured bacteria from surface samples collected within the Atacama Desert are limited in diversity, and the majority are members of Actinobacteria and Firmicutes. A small amount of Proteobacteria and Bacteroidetes has also been recovered (Bagaley 2006; Navarro-Gonzalez et al. 2003). More specifically, previously identified culturable bacteria belong to Geodermatophilaceae, Sphingomonas, Bacillus, Arthrobacter, Brevibacillus, Kocuria, Cellulomonas, Hymenobacter, Asticcacaulis, Mesorhizobium, Bradyrhizobium, Afipia, Alphaproteobacteria, and Betaproteobacteria (Gómez-Silva et al. 2008; Lester et al. 2007). On our agar plates, these bacterial taxa act as representatives of the whole microbial community from their sampled sites. Thus, the manner of growth and the change in CFUs of our cultivation experiments primarily reflect the preferences of bacteria within these taxa.

The water amendment experiments suggest that active culturable microorganisms are not impaired by rainfall that is less than $1 \mathrm{~mm}$ per day, as the volumes of water we added to these agar plates. Although the proliferation of some of these microbes manifested a decreasing trend after the abrupt water wash, more microbes benefited from the addition of water (Figure $7 \&$ Table S4). However, when precipitation reaches as high as the two unprecedented rainfall events ( $38.6 \mathrm{~mm}$ and $19.6 \mathrm{~mm}$, respectively) in a few days, massive water input can dissolve soluble salts and concentrate them down to more $20 \mathrm{~cm}$ depth (Davis et al. 2010; Marion et al. 2008; Shen et al. 2019). Amendments with excessive dissolved sodium chloride and sodium carbonate inhibited the growth of active microorganisms on agar plates; amendments with excessive dissolved sodium sulfate and sodium acetate made no difference in microbial growth; only excessive sodium L-lactate amendments promoted the growth of active culturable microbes (Figure 7 \& Table S5). Unfortunately, since organic C salts are limited in the oxidizing natural environment of the Atacama Desert (Azua-Bustos et al. 2017; Connon et al. 2007; Navarro-Gonzalez et al. 2003; Quinn et al. 2007), the dissolved materials and the extreme water addition might only harm the indigenous microbial communities (Azua-Bustos et al. 2018; Fernandez-Martinez et al. 2019), at least in the short term.

In comparison with the results of microbial cultures, the negative correlations between total organic carbon (an approximation of all grain-bound biomass) (Azua-Bustos et al. 2012a; Azua-Bustos et al. 2009; Ewing et al. 2008; Lester et al. 2007; Shen et al. 2019) and sediment sodium/ sediment chloride within the hyperarid core (Figure $6 a, b$ ) are consistent with the negative effects of sodium chloride and some other sodium salts on microbial proliferation (Figure 7 \& Table S5) (Bagaley 2006). However, TOC content in the hyperarid core is positively associated with water soluble chloride (Figure 6c). This inconsistency 
of the relationships between microbial biomass and chloride in different forms might be explained as that: some chloride minerals such as halite are highly hygroscopic; the deliquescence process within chloride minerals provide moisture to microbial communities that inhabit inside (Davila et al. 2008; Davila et al. 2013; Finstad et al. 2017; Pfeiffer et al. 2019; Wierzchos et al. 2012); the soluble chloride concentration might indicate the portion of chloride that deliquesces. The positive correlation between TOC and soluble chloride might indirectly reflect the beneficial effect of salt deliquescence on microbial biomass, but not a benefit directly from chloride ions.

Furthermore, water soluble sulfate also contributes to microbial biomass as a long-term outcome (Figure 6d), which again does not agree with salt amendment experiments (Figure 7 \& Table S5). Since sulfate in the Atacama Desert is usually formed in hydrated forms (e.g., gypsum, Figure 2), more sulfate indicates the larger proportions of gypsum that can potentially provide crystallization water to nearby microorganisms (Palacio et al. 2014). Additionally, these microorganisms can reduce sulfate for energy production and sulfur assimilation (Figure 12 \& Table 3). Therefore, higher sulfate concentrations can both elevate the moisture in a microhabitat and supply nutrients for microbial life.

\subsection{Salt distributions and microbial communities along the aridity gradient}

The degree of influence of water on life in desert environments is not entirely clear, and the paradigm defining the relationship between precipitation and ecosystem processes in arid environments has recently been questioned. In particular, this debate has proposed revisions to the "pulse-reserve" model that depicts rainfall as the dominant limiting factor for life in arid ecosystems (Reynolds et al. 2004; Schwinning et al. 2004). Our results indicate that microbial communities in Atacama soils were influenced by a variety of environmental factors including elevation, $\mathrm{pH}$, conductivity, $\mathrm{SOM}$, and various salts that change, for the most part, with latitude and aridity (Figure 10c) (Bossio et al. 1998; Doran et al. 1998; Drenovsky et al. 2004; Gallardo and Schlesinger 1992; Phelps et al. 1994; Zeglin et al. 2009). At southern latitudes, the decrease in aridity and salt concentrations yielded soils that were relatively higher in microbial abundance and diversity (Figure 4 \& Figure 5 \& Table 2 \& Table S3), while northern soils were less amenable to life, producing low diversity microbial communities with decreased activity and abundance (Jones et al. 2018; Schulze-Makuch et al. 2018).

Although the diversity of unknown phyla is high (Contador et al. 2019), the relative abundance of these species were not outstanding at all in our study sites (Figure 9). Soils of the southern arid desert were heterogenous in microbial composition and dominated by Actinobacteria, Proteobacteria, Chloroflexi, Firmicutes, Acidobacteria, Planctomycetes, Bacteroidetes, Gemmatimonadetes, and Verrucomicrobia (Figure 9), phyla commonly detected in arid desert environments (Connon et al. 2007; Drees et al. 2006; Fernandez-Martinez et al. 2019; Holmes et al. 2000; Mandakovic et al. 2018; Meslier et al. 2018; Neilson 
et al. 2012; Smith et al. 2006). Hyperarid soils were shown to be homogenously composed of two phyla - Deinococcus-Thermus and Aquificae, which when combined represented $~ 94 \%$ of the soil microorganisms detected there. The other characteristic bacterial phyla in hyperarid AT-12 include Acetothermia, Armatimonadetes, Hydrothermae, and Thermotogae, bacteria within which generally adapt to nutrient-depleted and high temperature conditions (Hao et al. 2018; Jungbluth et al. 2017; Lee et al. 2014). Actinobacteria survived in the pre-rainfall hyperarid core of the Atacama Desert in 2012 were only belong to 9 species - uncultured Ilumatobacteraceae, Corynebacterium sp., Micrococcus sp., Lawsonella sp., uncultured Geodermatophilus sp., uncultured Rothia sp., uncultured MB-A2-108, uncultured RBG-16-55-12, and unclassified Acidimicrobiia. All species in classes Nitriliruptoria, Rubrobacteria, and Thermoleophilia, and most of species in classes Actinobacteria and Acidimicrobiia have disappeared after decades or centuries of the extreme hyperaridity, similar to the microbiota structure of the salt flat ecosystems in the Atacama Desert (Farias et al. 2014; Farias et al. 2013; Ley et al. 2006; Mobberley et al. 2012; Rasuk et al. 2016; Rasuk et al. 2014; Sahl et al. 2008). Besides the long-term hyperaridity, the deficiency of extractable Actinobacteria in hyperarid AT-12 may be also caused by incomplete extraction or sequencing because of the limit of technology and the novelty of extremophilic actinobacterial species (Goodfellow et al. 2018; Idris et al. 2017). Additionally, some Actinobacteria such as its classes Actinobacteria, Acidimicrobiia, and Rubrobacteria can form spores that are difficult to break down during DNA extraction to counterattack ultraviolet radiation and dehydration (Barka et al. 2016). Analogously, the decreasing proportions of Firmicutes (majorly Bacilli, and minorly Clostridia, Erysipelotrichia, and Limnochordia) in the hyperarid core may be a result of their sporulation (Rose et al. 2011).

Deinococcus-Thermus has also been detected in calcites, halites, microbialites, and gypsum evaporites of the Atacama Desert (DiRuggiero et al. 2013; Farias et al. 2017; Fernandez et al. 2016; Rasuk et al. 2016). Deinococcus-Thermus bacteria possess a variety of adaptations to persist extreme soil conditions that are hypersaline, extremely dry, highly oxidizing and irradiative (Battistuzzi and Hedges 2009; Neilson et al. 2012; Paulino-Lima et al. 2013; Paulino-Lima et al. 2016; Perfumo et al. 2011). After heavy rains, within the phylum of Deinococcus-Thermus, dominance shifted from of the order Thermales, who are mostly thermoresistant, to a dominance of the order Deinococcales, who are both thermoresistant and radioresistant (Battista et al. 1999; Omelchenko et al. 2005). This shift might be triggered by the negative facet of water-driven microbial metabolic activation: since water woke dormant microbes up; these microbes disarmed sporulation and confronted the harsh ambient conditions, especially ionizing irradiation (Armstrong et al. 2016; Stevenson et al. 2015). Therefore, the Deinococcus-Thermus population shifted to a more Deinococcales-dominant structure. 
Excitingly, this is the first discovery of bacteria belonging to the phylum Aquificae in the Atacama Desert, and especially of such a high abundance in any desert soils (Huang et al. 2011; Prieto-Barajas et al. 2018). Three uncultured Thermocrinis species in family Aquificaceae and one unspecified species in family Hydrogenothermaceae. In general, members of the phylum Aquificae are non-spore-forming and strictly thermophilic with an optimal growth temperature above $65^{\circ} \mathrm{C}$ (Griffiths and Gupta 2006; Horiike et al. 2009). Although conditions in subsurface soils of the Atacama are not within the optimal growth range, Aquificae bacteria have evolved enzyme-mediated adaptative mechanisms to counter oxidative stresses (Deckert et al. 1998), and they can autotrophically perform carbon fixation, sulphite oxidation, as well as hydrogen oxidation to water (Gupta and Lali 2013; Huber et al. 1992; L'Haridon et al. 2006). Species of Aquificaceae and Hydrogenothermaceae were branched early in the phylogenetical history (Acca et al. 1994; Coenye and Vandamme 2004; Hugler et al. 2007).

After the two heavy rainfall events during 2015 and 2017, soluble salts at the shallow subsurface of soils have been dissolved and transported to depth (Figure 3 \& Table S1). For example, the proportions of brushite and gypsum which contain crystallized water molecules increased in PONR and Yungay where heavy rainfalls had the largest affect (Figure 2 \& Figure S1). Visible vegetation on the ground surface migrated to a more northern site from TZ-5 in 2012 to TZ-4 in 2017. The nearby microbiomes should concomitantly benefit from and fight against the excessive water and dissolved salts. The microbial diversity in the hyperarid AT-17 site, MES, became higher compared to the hyperarid AT-12 sites (Table 2 \& Figure 8 \& Figure S2). However, the structure of microbial communities in the hyperarid region completely shifted toward a pattern that is more common in the southern transition zone, to one dominated by Actinobacteria, Proteobacteria, and Chloroflexi (Figure 9 \& Figure 10a, b). This shift indicates the occurrence of a water-driven microbial community perturbation and reorganization in the hyperarid core (Dion 2008; Edwards 1990; Fernandez-Martinez et al. 2019). The intra-site similarity of microbial composition were $\sim 80 \%$ (Figure 10a), and the similarity of a site within the transition zone between the 2012 and 2017 samplings still remained at high percentages, 60\%-80\%. The intra-site similarity of microbial composition were $\sim 80 \%$ (Figure 10a), and the similarity of a site within the transition zone between the 2012 and 2017 samplings still remained at high percentages, 60\%-80\%. These similarity results imply that the precipitation in the transition zone caused little change in the microbial communities during the 5 years between 2012 and 2017.

\subsection{Microbial functions and metabolic responses}

Desert soils are exhausted in many of the essential requirements that nurture life, including water, carbon, and nutrients. As a result, desert soil microbial communities are primarily composed of microbes adapted to withstand harsh environmental conditions, and adept at exploiting the scarce 
nutritional resources necessary for growth. In recent years, these microbiomes have also survived occasional rainfalls which can lead to disastrous destruction of indigenous microbial communities (Armstrong et al. 2016; Azua-Bustos et al. 2018; Uritskiy et al. 2019). In this study, both the hyperarid and transition soils were dominated primarily by bacterial phyla capable of withstanding harsh desert conditions and water osmotic stress both before and after the rains. Potentially existent Martian organisms should evolve similar mechanisms over their history of resistance to the capricious Martian environments.

In 2012 when massive rainfall had not disturbed hyperarid soils for at least several decades (Hartley et al. 2005; Jordan et al. 2019; McKay et al. 2003), the hyperarid sites possessed the lowest proportions of nearly all metabolisms and all extreme response pathways. However, microorganisms living there had high proportions of pathways that mainly focus on syntheses of biomolecules such as nucleic acids, metabolic regulators, secondary metabolites, and cell structure molecules (Figure 11). Microbial communities were less frequently contacted in hyperarid soils (Figure 13), so individual microorganisms had to rely on themselves for the constructions of essential biomolecular compounds. In 2017, hyperarid microbiomes showed an increased proportion of other classifications of functional pathways (Figure $11 \&$ Table 3), reflecting slightly more metabolic diversity. On the other hand, the transition zone possessed the highest diversity of metabolisms (Figure $11 \&$ Table 3) and consistently fostered more frequently interacted microbial communities (Neilson et al. 2017) with more complete recycling of substrates between individual organisms (Figure 13). Notably, these communities can coevolve to establish a more resilient biosphere for survival under extreme circumstances.

Recent studies have revealed that the hyperarid Antarctic Dry Valley soils similarly support microbial communities of greater complexity and diversity than previously described (Cowan et al. 2002; Pointing et al. 2009). The composition of soil microbial communities from the Atacama Desert and the Antarctic Dry Valley appear to be regulated by different environmental factors, suggesting that not all extremely arid environments function similarly. Nevertheless, these environments offer a unique perspective on the challenges of overcoming the inhospitable conditions for life in desert soils, and yield an increased understanding of the environmental factors controlling life and their functions in extremely arid habitats.

On Mars, nocturnal availability of a thin layer of liquid water at subsurface (Altheide et al. 2009; Chevrier et al. 2009; Cull et al. 2010; Kereszturi and Rivera-Valentin 2012; Martinez and Renno 2013; Meslin et al. 2013) can nourish indigenous Martian "microbes" and allow them to slowly thrive with daily small amount of moisture amendments (Figure 7 \& Table S4) (Stevenson et al. 2015). The cycle of desiccation and rewetting decomposes dead microbial materials to release intracellular organics and 
uncovers concealed SOM by smashing soil aggregates (Armstrong et al. 2016), which furthermore offers nutrients to alive microorganisms that are evoked by liquid water from dormancy. However, most microorganisms are vanished when drown in brine (Azua-Bustos et al. 2018). Thus, our findings suggest feasibly detectable Martian "life" may concentrate at the regions of temperate temperature, i.e., around the equatorial regions, and during the day time after the evaporation of the film of liquid brine.

\section{Conclusions}

Subjected to millions of years of extreme aridity, soils of the Atacama Desert have become transformed into an inhospitable Mars-analogous environment that is unique even among other extremely arid environments. The Atacama microbial communities are one of the least diverse biological communities on Earth based on all alpha diversity indices (Lester et al. 2007; Maier et al. 2004; Navarro-Gonzalez et al. 2003). Our results indicate a large disparity between hyperarid and arid soils in soil microbial viability, diversity, activity, metabolism, network, and community composition. As soils become drier toward the north, biological activity decreases, with microbial viability, diversity, and network significantly reduced under hyperarid conditions. Thus, our data support the hypothesis that the dry limit of microbial life is reached in the hyperarid soils of the Atacama (Azua-Bustos et al. 2012b; Barros et al. 2008; Navarro-Gonzalez et al. 2003). We have additionally shown that a variety of factors influence soil microbial communities, including environmental and physiological conditions. Increased precipitation and nutrient availability in the southern transition sites correlated with more diverse and more closely allied soil microbial communities, while soils of the hyperarid sites consisted of more metabolically inactive cells exhibiting low phylogenetic diversity. Confronting the challenges brought by the water and salt shocks as the aftermath of two recent massive precipitations, microbial communities in the hyperarid region shifted to a structure that is common in the southern transition zone. Although the microbial compositions and metabolic functions did not recover to the pre-rainfall level (Armstrong et al. 2016; Fernandez-Martinez et al. 2019; Uritskiy et al. 2019), the diversity of microbiomes and metabolisms was slightly increased within 6 months of these extreme rainfall events. We therefore can infer similar events that may have happened on the wetter early Mars, as well as during the drying-rewetting cycle on the present Mars.

\section{Availability of supporting data}

The raw sequencing data for microbiome analyses of AT-12 and AT-17 in this study are available from the National Center for Biotechnology Information (NCBI) under BioProject ID PRJNA595727 and PRJNA595740, respectively.

\section{Author contributions}


JS, AZ, MC, and TS sampled the study sites in 2012 and 2017. JS and AW extracted and sequenced DNA of 2017 Atacama soil samples. TS performed soil characterizations and DNA extraction and sequencing of 2012 Atacama soil samples. JS performed ion chromatography measurements under the supervision of MC, sequence and function analyses under the supervision of $\mathrm{AW}$, microbial cultivations, network analyses, and all statistical analyses. JS created all figures and tables. All authors wrote and approved the final manuscript. Data curation, JS; Funding acquisition, MC, TS, and AW; Investigation, JS and TS; Methodology, JS, AW, and TS; Project administration, AZ and MC; Software, JS and AW; Supervision, AZ and MC; Validation, AZ, MC, and AW; Visualization, JS; Writing-original draft, JS; Writing-review \& editing, TS, AW, AZ, and MC.

\section{Funding}

This research was funded by European Research Council (ERC) under the European Union's Horizon 2020 Research and Innovation Programme (Grant Agreement 678812) (to MC) for 2017 sampling and various geochemical characterizations, and John Templeton Foundation (Grant Agreement 60501) (to AW) for DNA extraction and sequencing. JS also acknowledges support from the China Scholarship Council (CSC). We thank the Alabama Space Grant Consortium / NASA Training Grant NNX10AJ80H provided to TS for 2012 sample analyses. We thank the Lewis and Clark Fund for Exploration and Field Research in Astrobiology for funds to conduct 2012 sampling.

\section{Conflict of Interest Statement}

The authors declare that the research was conducted in the absence of any commercial or financial relationships that could be construed as a potential conflict of interest.

\section{Acknowledgments}

We thank Matthew Holden in the School of Medicine, University of St Andrews, for generously providing the Illumina MiSeq sequencing system. We thank Kerry Pettigrew in the School of Medicine, University of St Andrews, for assisting with Qubit DNA quantitation. We thank Claire Cousins, Lotta Purkamo, and Mark Fox-Powell in the School of Earth and Environmental Sciences, University of St Andrews, for useful discussions upon microbiological analyses. We thank Lucy McKay and Emma Robertson for facilitating ion chromatography measurements. Thanks also to Eric Roden and Brandon Converse at the University of Wisconsin-Madison for 454 sequencing, and Alison Church-Bird at Auburn University for assistance with the flow cytometer.

\section{Supplementary materials}
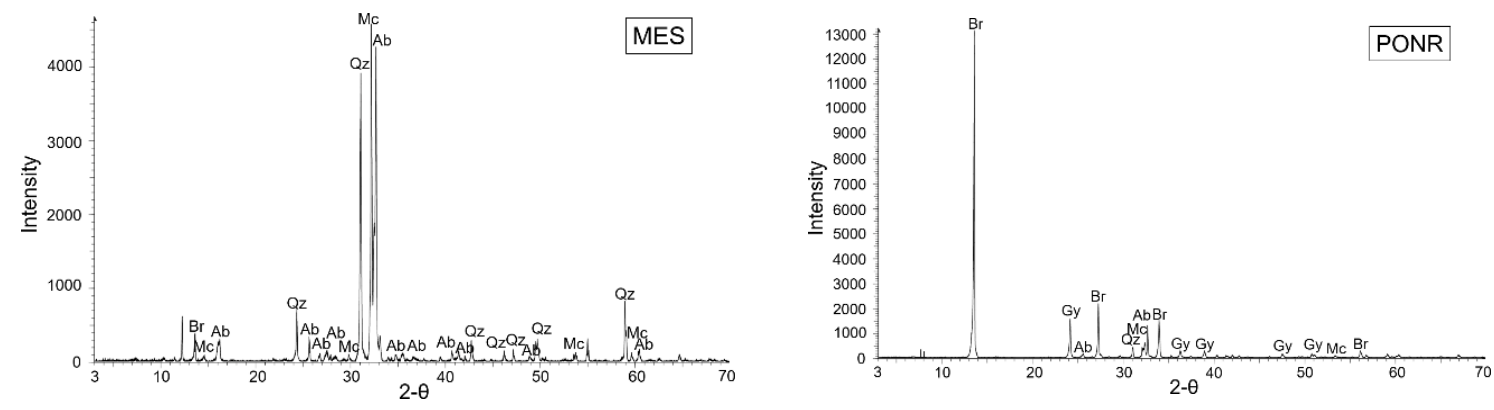
(a)

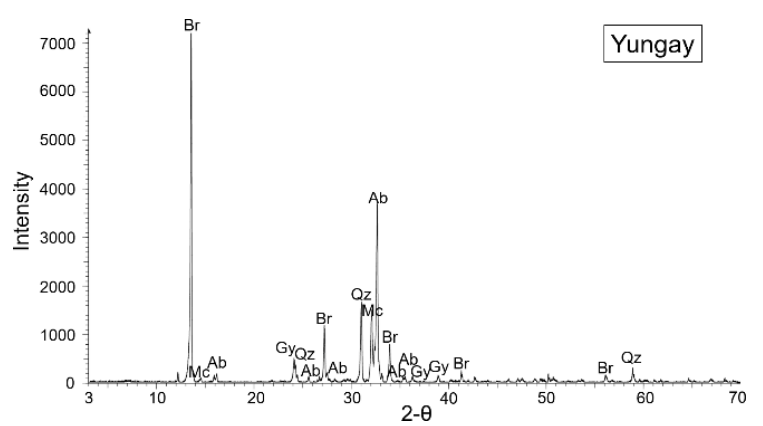

(c)

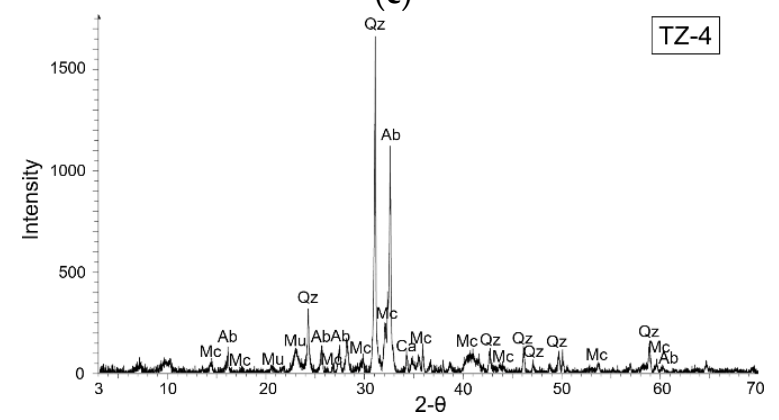

(e)

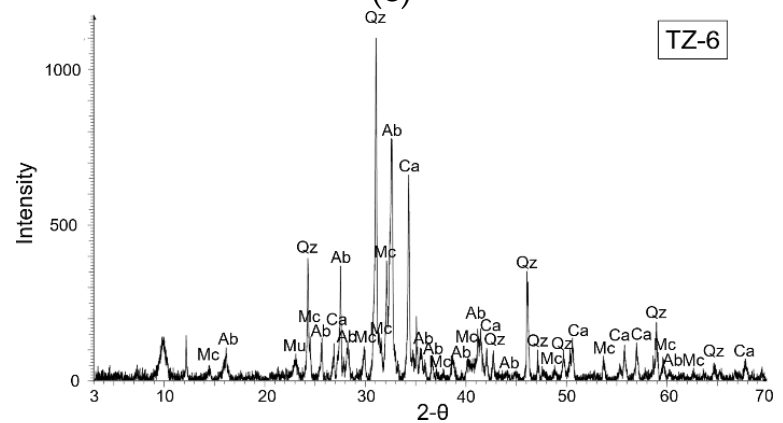

(g) (b)

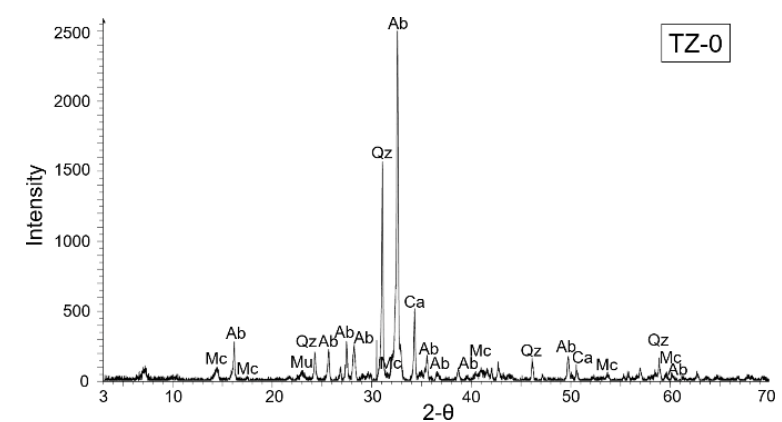

(d)

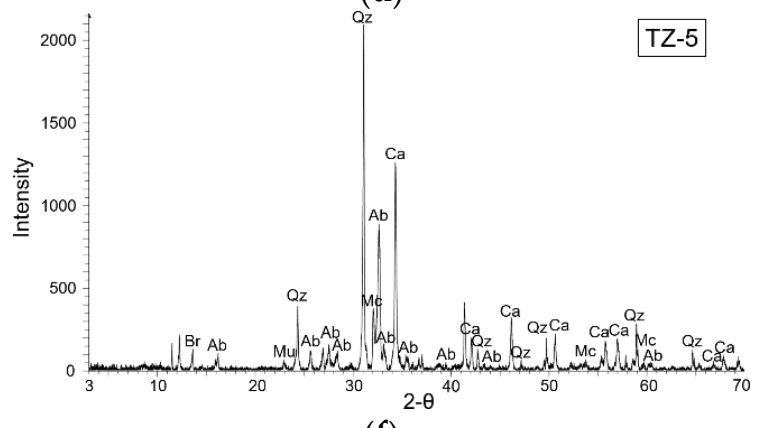

(f)

Figure S1. Mineral compositions of AT-17 soils determined X-ray diffraction (XRD) analysis. (Qz, quartz; Ab, albite; $\mathrm{Br}$, brushite; $\mathrm{Gy}$, gypsum; $\mathrm{Mu}$, muscovite; $\mathrm{Ca}$, calcite; $\mathrm{Mc}$, microcline)

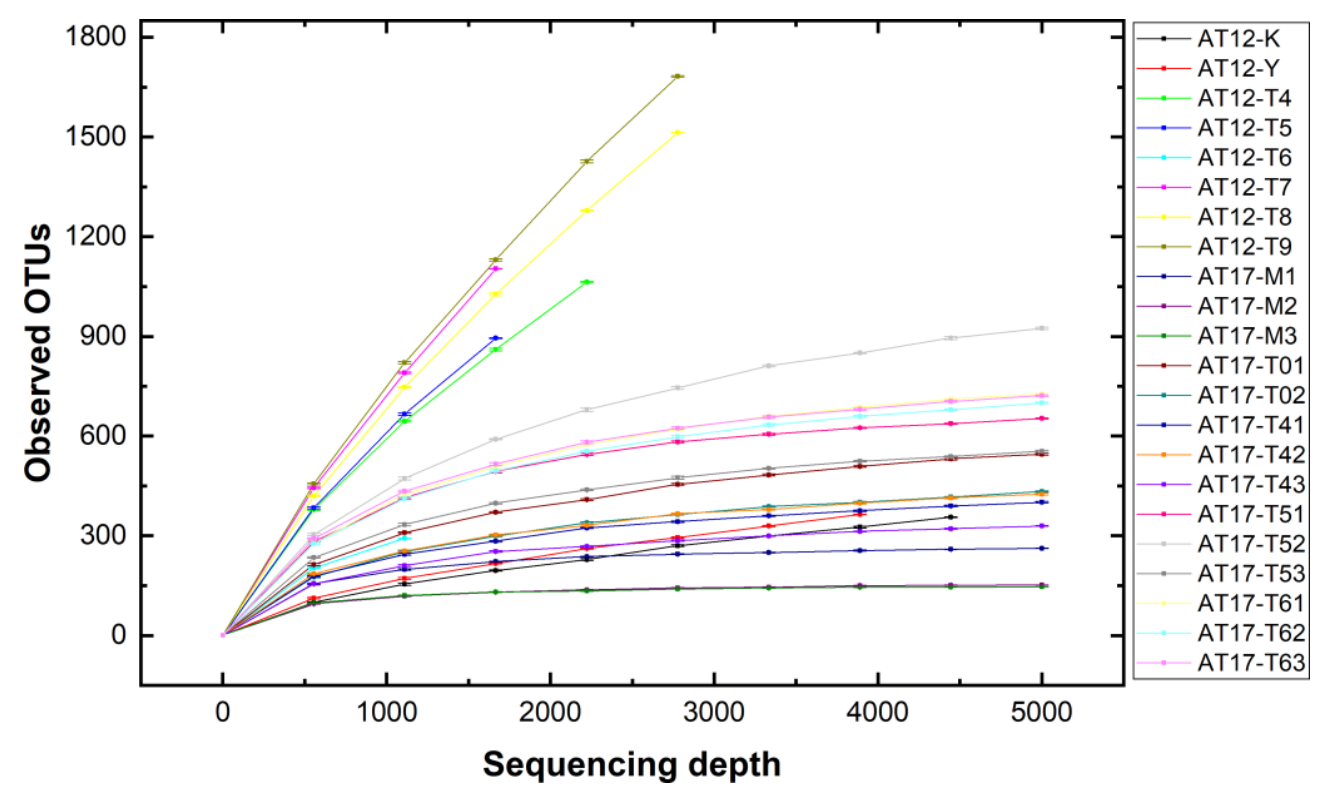


Figure S2. Observed OTUs richness as a function of the number of sequences per sample at 5,000 sampling depth. An OTU definition of sequence homology at or above $99 \%$. Error bars of rarefaction analysis were shown. Abbreviations as in Table 2.

Table S1. Concentrations (means \pm standard errors) of soluble chloride, nitrate, and sulfate in samples from 2012 and 2017.

\begin{tabular}{|c|c|c|c|c|}
\hline & Sample & $\mathrm{Cl}^{-}(\mathrm{ppm})$ & $\mathrm{NO}_{3}{ }^{-}(p p m)$ & $\mathrm{SO}_{4}^{2-}(\mathrm{ppm})$ \\
\hline \multirow{10}{*}{ AT-12 } & KM40 & $175895.0 \pm 12168.4$ & $15914.9 \pm 1131.8$ & $76503.5 \pm 6069.6$ \\
\hline & MES & $41.8 \pm 2.9$ & $153.1 \pm 10.8$ & $41042.3 \pm 3367.2$ \\
\hline & PONR & $12201.6 \pm 848.9$ & $16371.7 \pm 1159.8$ & $77450.6 \pm 6354.2$ \\
\hline & Yungay & $137.9 \pm 7.8$ & $148.1 \pm 2.6$ & $28776.7 \pm 1852.3$ \\
\hline & TZ-4 & $3.0 \pm 0.02$ & $2.4 \pm 0.03$ & $11.3 \pm 0.03$ \\
\hline & $\mathrm{TZ}-5$ & $582.8 \pm 39.6$ & $533.5 \pm 37.6$ & $374.8 \pm 29.6$ \\
\hline & TZ-6 & $1300.8 \pm 90.0$ & $39.2 \pm 2.4$ & $292.9 \pm 22.4$ \\
\hline & $\mathrm{TZ}-7$ & \multicolumn{3}{|c|}{ Samples not collected } \\
\hline & TZ-8 & $9.8 \pm 0.04$ & $11.3 \pm 0.03$ & $24.7 \pm 0.06$ \\
\hline & TZ-9 & $8.0 \pm 0.03$ & $14.4 \pm 0.04$ & $16.6 \pm 0.06$ \\
\hline \multirow{21}{*}{ AT-17 } & MES pit 1 & $7.5 \pm 0.1$ & $35.7 \pm 0.3$ & $260.4 \pm 3.2$ \\
\hline & MES pit 2 & $71.4 \pm 1.2$ & $238.4 \pm 3.6$ & $4948.0 \pm 60.5$ \\
\hline & MES pit 3 & $8.5 \pm 0.1$ & $52.1 \pm 0.2$ & $5865.3 \pm 24.6$ \\
\hline & PONR pit 1 & $54.3 \pm 1.6$ & $147.5 \pm 2.5$ & $14108.4 \pm 333.1$ \\
\hline & PONR pit 2 & $226.7 \pm 22.6$ & $362.0 \pm 39.1$ & $19520.1 \pm 3172.1$ \\
\hline & PONR pit 3 & $65.5 \pm 2.0$ & $157.7 \pm 2.6$ & $16093.5 \pm 333.0$ \\
\hline & Yungay pit 1 & $16.4 \pm 0.9$ & $23.8 \pm 0.1$ & $15840.4 \pm 248.4$ \\
\hline & Yungay pit 2 & $14.0 \pm 0.2$ & $19.3 \pm 1.0$ & $16941.8 \pm 1398.0$ \\
\hline & Yungay pit 3 & $11.5 \pm 0.8$ & $15.5 \pm 0.3$ & $15672.4 \pm 190.0$ \\
\hline & TZ-0 pit 1 & $7.0 \pm 0.1$ & $1.9 \pm 0.0$ & $16.7 \pm 0.3$ \\
\hline & TZ-0 pit 2 & $4.1 \pm 0.1$ & $1.4 \pm 0.0$ & $25.7 \pm 0.4$ \\
\hline & TZ-0 pit 3 & $6.2 \pm 0.1$ & $2.5 \pm 0.0$ & $28.2 \pm 0.3$ \\
\hline & TZ-4 pit 1 & $3029.6 \pm 27.8$ & $3002.3 \pm 26.8$ & $165.9 \pm 2.2$ \\
\hline & TZ-4 pit 2 & $5040.2 \pm 48.6$ & $7448.2 \pm 66.7$ & $338.9 \pm 3.5$ \\
\hline & TZ-4 pit 3 & $2615.0 \pm 26.5$ & $4456.0 \pm 43.6$ & $1212.0 \pm 13.5$ \\
\hline & TZ-5 pit 1 & $38.2 \pm 0.4$ & $3.0 \pm 0.1$ & $13.7 \pm 0.1$ \\
\hline & TZ-5 pit 2 & $328.9 \pm 2.5$ & $6.0 \pm 0.1$ & $1606.4 \pm 10.7$ \\
\hline & TZ-5 pit 3 & $3132.1 \pm 19.9$ & $20.9 \pm 0.2$ & $3564.0 \pm 18.9$ \\
\hline & TZ-6 pit 1 & $113.9 \pm 0.8$ & $11.7 \pm 0.2$ & $95.9 \pm 0.8$ \\
\hline & TZ-6 pit 2 & $2981.5 \pm 18.5$ & $140.6 \pm 1.3$ & $1660.8 \pm 10.3$ \\
\hline & TZ-6 pit 3 & $1269.0 \pm 9.8$ & $82.4 \pm 0.8$ & $489.4 \pm 3.9$ \\
\hline
\end{tabular}

Table S2. Bacterial viability and abundance within AT-12 soils determined by cytometric analysis and within AT17 soil determined by trypan blue staining assay.

\begin{tabular}{|c|c|c|c|c|c|}
\hline \multicolumn{2}{|c|}{ Sample } & $\begin{array}{l}\log (\text { viable } \\
\text { cells/g) }\end{array}$ & $\begin{array}{l}\text { log(non-viable } \\
\text { cells/g) }\end{array}$ & $\begin{array}{l}\log (\text { total } \\
\text { cells/g) }\end{array}$ & $\begin{array}{l}\text { viable : non-viable } \\
\text { (cells/cells) }\end{array}$ \\
\hline \multirow{3}{*}{ AT-12 } & KM40 & 6.15 & 6.48 & 6.70 & 0.46 \\
\hline & TZ-4 & 6.54 & 6.06 & 6.68 & 3.04 \\
\hline & TZ-5 & 6.70 & 6.90 & 7.15 & 0.63 \\
\hline
\end{tabular}




\begin{tabular}{rccccc} 
& TZ-6 & 6.70 & 6.59 & 7.00 & 1.28 \\
TZ-7 & 6.71 & 6.83 & 7.23 & 0.77 \\
TZ-8 & 6.67 & 6.59 & 6.96 & 1.20 \\
AT-17-9 & 6.66 & 6.25 & 6.83 & 2.59 \\
\hline \hline \multirow{5}{*}{ MES } & 6.67 & 5.76 & 6.72 & 8.04 \\
& PONR & 6.25 & 5.67 & 6.35 & 3.81 \\
& Yungay & 6.32 & 5.78 & 6.43 & 6.07 \\
& TZ-0 & 6.77 & 5.99 & 6.84 & 1.24 \\
& TZ-4 & 6.53 & 6.43 & 6.78 & 0.73 \\
& TZ-5 & 6.26 & 6.39 & 6.66 & 2.15 \\
\hline
\end{tabular}

Table S3. Colony forming units (CFUs) of AT-17 soil samples on tryptic soy agar, LB agar, and plate count agar plates without amendments, amended with water, and amended with $10 \%$ sodium chloride, $10 \%$ sodium sulfate, $10 \%$ sodium carbonate, $10 \%$ sodium acetate, and $10 \%$ sodium L-lactate.

\begin{tabular}{|c|c|c|c|c|c|c|c|c|}
\hline $\begin{array}{l}\text { Type of culture } \\
\text { plate }\end{array}$ & Amendment & MES & PONR & Yungay & TZ-0 & TZ-4 & TZ-5 & TZ-6 \\
\hline \multirow{9}{*}{$\begin{array}{l}\text { Tryptic soy } \\
\text { agar }\end{array}$} & None & 37 & 53 & 169 & 514 & $1.60 \times 10^{5}$ & $1.33 \times 10^{5}$ & $3.21 \times 10^{5}$ \\
\hline & $1.5 \mathrm{~mL} \mathrm{H}_{2} \mathrm{O}$ & 523 & 140 & 44 & 297 & $1.09 \times 10^{5}$ & $5.75 \times 10^{4}$ & $2.21 \times 10^{5}$ \\
\hline & $3 \mathrm{~mL} \mathrm{H}_{2} \mathrm{O}$ & 41 & 35 & $6.29 \times 10^{3}$ & 288 & $8.00 \times 10^{4}$ & $1.20 \times 10^{5}$ & $4.29 \times 10^{5}$ \\
\hline & $4.5 \mathrm{~mL} \mathrm{H}_{2} \mathrm{O}$ & $5.76 \times 10^{3}$ & $3.39 \times 10^{3}$ & $1.14 \times 10^{4}$ & 312 & $1.65 \times 10^{6}$ & $5.22 \times 10^{4}$ & $5.09 \times 10^{5}$ \\
\hline & Chloride & 7 & 12 & $3.6 \times 10^{4}$ & 181 & $4.21 \times 10^{4}$ & $8.70 \times 10^{5}$ & $5.26 \times 10^{5}$ \\
\hline & Sulfate & 22 & 5 & $1.28 \times 10^{4}$ & $1.18 \times 10^{3}$ & $2.80 \times 10^{5}$ & $3.47 \times 10^{5}$ & $5.16 \times 10^{5}$ \\
\hline & Carbonate & 394 & 10 & $2.69 \times 10^{4}$ & 7 & 298 & $5.44 \times 10^{4}$ & $3.68 \times 10^{5}$ \\
\hline & Acetate & 2 & 2 & 92 & 268 & $5.08 \times 10^{5}$ & $1.45 \times 10^{5}$ & $1.11 \times 10^{6}$ \\
\hline & L-lactate & $2.19 \times 10^{4}$ & 58 & $6.94 \times 10^{3}$ & 575 & $1.77 \times 10^{6}$ & $8.34 \times 10^{4}$ & $4.77 \times 10^{5}$ \\
\hline \multirow{9}{*}{ LB agar } & None & 17 & 28 & 33 & 91 & $2.39 \times 10^{5}$ & $2.95 \times 10^{3}$ & $5.41 \times 10^{4}$ \\
\hline & $1.5 \mathrm{~mL} \mathrm{H}_{2} \mathrm{O}$ & 71 & 54 & 13 & 140 & $8.18 \times 10^{3}$ & $1.81 \times 10^{3}$ & $1.65 \times 10^{5}$ \\
\hline & $3 \mathrm{~mL} \mathrm{H}_{2} \mathrm{O}$ & 37 & 93 & $7.51 \times 10^{3}$ & 241 & $2.67 \times 10^{4}$ & $4.93 \times 10^{3}$ & $1.14 \times 10^{5}$ \\
\hline & $4.5 \mathrm{~mL} \mathrm{H}_{2} \mathrm{O}$ & 7 & $7.98 \times 10^{3}$ & $3.71 \times 10^{3}$ & 491 & $1.23 \times 10^{6}$ & $1.17 \times 10^{3}$ & $1.54 \times 10^{5}$ \\
\hline & Chloride & 0 & 2 & 219 & 135 & $3.03 \times 10^{3}$ & 986 & $1.19 \times 10^{5}$ \\
\hline & Sulfate & 22 & 2 & 145 & 858 & $9.37 \times 10^{3}$ & $2.96 \times 10^{3}$ & $3.71 \times 10^{5}$ \\
\hline & Carbonate & $2.68 \times 10^{3}$ & 15 & 53 & 0 & 305 & $1.96 \times 10^{3}$ & $4.49 \times 10^{3}$ \\
\hline & Acetate & 10 & 5 & 243 & 358 & $5.44 \times 10^{5}$ & $4.35 \times 10^{3}$ & $6.01 \times 10^{5}$ \\
\hline & L-lactate & 162 & 184 & $1.10 \times 10^{4}$ & $1.08 \times 10^{3}$ & $3.28 \times 10^{6}$ & $6.21 \times 10^{3}$ & $4.27 \times 10^{5}$ \\
\hline \multirow{9}{*}{$\begin{array}{l}\text { Plate count } \\
\text { agar }\end{array}$} & None & 167 & 190 & $8.06 \times 10^{3}$ & $1.40 \times 10^{3}$ & $6.89 \times 10^{6}$ & $1.82 \times 10^{4}$ & $1.25 \times 10^{6}$ \\
\hline & $1.5 \mathrm{~mL} \mathrm{H}_{2} \mathrm{O}$ & 744 & $8.43 \times 10^{3}$ & $8.43 \times 10^{3}$ & 311 & $3.22 \times 10^{6}$ & $5.87 \times 10^{4}$ & $6.44 \times 10^{6}$ \\
\hline & $3 \mathrm{~mL} \mathrm{H}_{2} \mathrm{O}$ & $2.09 \times 10^{3}$ & 254 & $4.55 \times 10^{4}$ & 243 & $2.67 \times 10^{6}$ & $2.60 \times 10^{4}$ & $5.93 \times 10^{5}$ \\
\hline & $4.5 \mathrm{~mL} \mathrm{H}_{2} \mathrm{O}$ & $1.36 \times 10^{3}$ & $8.56 \times 10^{4}$ & $6.96 \times 10^{4}$ & 638 & $1.33 \times 10^{7}$ & $1.25 \times 10^{5}$ & $4.12 \times 10^{6}$ \\
\hline & Chloride & 2 & 53 & 29 & 237 & $1.89 \times 10^{6}$ & $5.80 \times 10^{4}$ & $5.68 \times 10^{5}$ \\
\hline & Sulfate & 94 & 880 & 0 & $9.18 \times 10^{3}$ & $6.09 \times 10^{6}$ & $5.80 \times 10^{4}$ & $4.18 \times 10^{5}$ \\
\hline & Carbonate & $1.61 \times 10^{3}$ & 176 & 174 & 53 & $4.35 \times 10^{3}$ & $6.38 \times 10^{4}$ & $1.74 \times 10^{5}$ \\
\hline & Acetate & 2 & 19 & 135 & 193 & $2.67 \times 10^{6}$ & $2.32 \times 10^{4}$ & $1.33 \times 10^{6}$ \\
\hline & L-lactate & $2.93 \times 10^{3}$ & 297 & $6.82 \times 10^{4}$ & $2.84 \times 10^{3}$ & $2.78 \times 10^{7}$ & $3.97 \times 10^{5}$ & $2.60 \times 10^{6}$ \\
\hline
\end{tabular}


Table S4. Results of cell cultures on tryptic soy agar, LB agar, and plate count agar plates with water amendments, recording the change in the order of magnitude of CFUs with water amendments (all numbers are scaled by logarithmic transformation and normalized as the difference from the plates without amendments). Positive effects of different volumes of water on microbial growth are bolded, and those caused increase in CFUs more than 1 and 2 orders of magnitude are labeled with ${ }^{*}$ and ${ }^{* *}$, respectively.

\begin{tabular}{|c|c|c|c|c|c|c|c|c|}
\hline $\begin{array}{l}\text { Type of culture } \\
\text { plate }\end{array}$ & Amendment & MES & PONR & Yungay & TZ-0 & TZ-4 & TZ-5 & TZ-6 \\
\hline \multirow{3}{*}{$\begin{array}{l}\text { Tryptic soy } \\
\text { agar }\end{array}$} & $1.5 \mathrm{~mL} \mathrm{H}_{2} \mathrm{O}$ & $1.15^{*}$ & 0.42 & -0.58 & -0.24 & -0.17 & -0.36 & -0.16 \\
\hline & $3 \mathrm{~mL} \mathrm{H}_{2} \mathrm{O}$ & 0.05 & -0.19 & $1.57^{*}$ & -0.25 & -0.30 & -0.05 & 0.13 \\
\hline & $4.5 \mathrm{~mL} \mathrm{H}_{2} \mathrm{O}$ & $2.20^{* *}$ & $1.80^{*}$ & $1.83^{*}$ & -0.22 & $1.01^{*}$ & -0.41 & 0.20 \\
\hline \multirow{3}{*}{ LB agar } & $1.5 \mathrm{~mL} \mathrm{H}_{2} \mathrm{O}$ & 0.63 & 0.29 & -0.41 & 0.19 & -1.47 & -0.21 & 0.49 \\
\hline & $3 \mathrm{~mL} \mathrm{H} \mathrm{H}_{2} \mathrm{O}$ & 0.34 & 0.53 & $2.36^{* *}$ & 0.42 & -0.95 & 0.22 & 0.32 \\
\hline & $4.5 \mathrm{~mL} \mathrm{H}_{2} \mathrm{O}$ & -0.36 & $2.46^{* *}$ & $2.06^{* *}$ & 0.73 & 0.71 & -0.40 & 0.45 \\
\hline \multirow{3}{*}{$\begin{array}{l}\text { Plate count } \\
\text { agar }\end{array}$} & $1.5 \mathrm{~mL} \mathrm{H}_{2} \mathrm{O}$ & 0.65 & $1.65^{*}$ & 0.02 & -0.65 & -0.33 & 0.51 & 0.71 \\
\hline & $3 \mathrm{~mL} \mathrm{H} \mathrm{H}_{2} \mathrm{O}$ & $1.10^{*}$ & 0.13 & 0.75 & -0.76 & -0.41 & 0.16 & -0.32 \\
\hline & $4.5 \mathrm{~mL} \mathrm{H}_{2} \mathrm{O}$ & 0.91 & $2.65^{* *}$ & 0.94 & -0.34 & 0.29 & 0.84 & 0.52 \\
\hline
\end{tabular}

Table S5. Results of cell cultures on tryptic soy agar, LB agar, and plate count agar plates with salt amendments, recording the change in the order of magnitude of CFUs with salt amendments (all numbers are scaled by logarithmic transformation and normalized as the difference from the plates with 4.5-mL water amendments). Negative effects of different salts on microbial growth are underlined, and those caused the decrease in CFUs more than $1,2,3$, and 4 orders of magnitude are labeled with ${ }^{*}, * * * *$, and ${ }^{* * *}$, respectively.

\begin{tabular}{|c|c|c|c|c|c|c|c|c|}
\hline $\begin{array}{l}\text { Type of culture } \\
\text { plate }\end{array}$ & Amendment & MES & PONR & Yungay & TZ-0 & TZ-4 & TZ-5 & TZ-6 \\
\hline \multirow{5}{*}{$\begin{array}{l}\text { Tryptic soy } \\
\text { agar }\end{array}$} & Chloride & $-2.90^{* *}$ & $-2.45^{* *}$ & 0.50 & -0.24 & $-1.59^{*}$ & 1.22 & 0.01 \\
\hline & Sulfate & $-2.42^{* *}$ & $-2.85^{* *}$ & 0.05 & $\overline{0.58}$ & -0.77 & 0.82 & 0.01 \\
\hline & Carbonate & $-1.16^{*}$ & $-2.54^{* *}$ & 0.38 & $\underline{-1.63^{*}}$ & $-3.744^{* * *}$ & 0.02 & $\underline{-0.14}$ \\
\hline & Acetate & $-3.38^{* * *}$ & $-3.15^{* * *}$ & $-2.09^{* *}$ & -0.07 & -0.51 & 0.44 & 0.34 \\
\hline & L-lactate & $\overline{0.58}$ & $-1.77^{*}$ & $\underline{-0.21}$ & $\overline{0.27}$ & $\overline{0.03}$ & 0.20 & $\underline{-0.03}$ \\
\hline \multirow{5}{*}{ LB agar } & Chloride & $\underline{-0.86}$ & $-3.52^{* * *}$ & $-1.23^{*}$ & $\underline{-0.56}$ & $-2.61^{* *}$ & $\underline{-0.08}$ & $\underline{-0.11}$ \\
\hline & Sulfate & $\overline{0.48}$ & $-3.52^{* * *}$ & $-1.41^{*}$ & $\overline{0.24}$ & $-2.12^{* *}$ & $\overline{0.40}$ & $\overline{0.38}$ \\
\hline & Carbonate & 2.57 & $-2.74^{* *}$ & $\overline{-1.84}^{*}$ & $-2.69^{* *}$ & $-3.60^{* * *}$ & 0.22 & $-1.54^{*}$ \\
\hline & Acetate & 0.12 & $-3.22^{* * *}$ & $-1.18^{*}$ & $\overline{-0.14}$ & $\underline{-0.35}$ & 0.57 & $\overline{0.59}$ \\
\hline & L-lactate & 1.35 & $-1.64^{*}$ & 0.47 & 0.34 & 0.43 & 0.72 & 0.44 \\
\hline \multirow{5}{*}{$\begin{array}{l}\text { Plate count } \\
\text { agar }\end{array}$} & Chloride & $-2.75^{* *}$ & $-3.21^{* * *}$ & $-3.38^{* * *}$ & $\underline{-0.43}$ & $\underline{-0.85}$ & $\underline{-0.33}$ & $\underline{-0.86}$ \\
\hline & Sulfate & $-1.16^{*}$ & $-1.99^{*}$ & $-\underline{-4.84^{* * * * *}}$ & $\overline{1.16}$ & $\overline{-0.34}$ & $-\underline{-0.33}$ & $\overline{-0.99}$ \\
\hline & Carbonate & 0.07 & $-2.69^{* *}$ & $-2.60^{* *}$ & $\underline{-1.08}^{*}$ & $-3.49^{* * *}$ & -0.29 & $-1.37^{*}$ \\
\hline & Acetate & $-2.75^{* *}$ & $-3.65^{* * *}$ & $-2.71^{* *}$ & -0.52 & $\underline{-0.70}$ & $\underline{-0.73}$ & $-\underline{-0.49}$ \\
\hline & L-lactate & $\overline{0.33}$ & $\underline{-2.46}^{* *}$ & $\overline{-0.01}$ & $\overline{0.65}$ & $\overline{0.32}$ & $\overline{0.50}$ & $\underline{-0.20}$ \\
\hline
\end{tabular}




\section{References}

Origin(Pro). OriginLab Corporation, Northampton, MA, USA.

Acca M., Bocchetta M., Ceccarelli E., Creti R., Stetter K. O., and Cammarano P. (1994) Updating Mass and Composition of Archaeal and Bacterial-Ribosomes - Archaeal-Like Features of Ribosomes from the DeepBranching Bacterium Aquifex Pyrophilus. Systematic and Applied Microbiology, 16: 629-637.

Altheide T., Chevrier V., Nicholson C., and Denson J. (2009) Experimental investigation of the stability and evaporation of sulfate and chloride brines on Mars. Earth and Planetary Science Letters, 282: 69-78.

Armstrong A., Valverde A., Ramond J. B., Makhalanyane T. P., Jansson J. K., Hopkins D. W., Aspray T. J., Seely M., Trindade M. I., and Cowan D. A. (2016) Temporal dynamics of hot desert microbial communities reveal structural and functional responses to water input. Scientific Reports, 6.

Artz R. R. E., Townend J., Brown K., Towers W., and Killham K. (2005) Soil macropores and compaction control the leaching potential of Escherichia coli O157 : H7. Environmental Microbiology, 7: 241-248.

Azua-Bustos A., Caro-Lara L., and Vicuna R. (2015) Discovery and microbial content of the driest site of the hyperarid Atacama Desert, Chile. Environmental Microbiology Reports, 7: 388-394.

Azua-Bustos A., Fairen A. G., Gonzalez-Silva C., Ascaso C., Carrizo D., Fernandez-Martinez M. A., FernandezSampedro M., Garcia-Descalzo L., Garcia-Villadangos M., Martin-Redondo M. P. and others. (2018) Unprecedented rains decimate surface microbial communities in the hyperarid core of the Atacama Desert. Scientific Reports, 8.

Azua-Bustos A., Gonzalez-Silva C., Arenas-Fajardo C., and Vicuna R. (2012a) Extreme environments as potential drivers of convergent evolution by exaptation: the Atacama Desert Coastal Range case. Frontiers in Microbiology, 3.

Azua-Bustos A., Gonzalez-Silva C., and Corsini G. (2017) The Hyperarid Core of the Atacama Desert, an Extremely Dry and Carbon Deprived Habitat of Potential Interest for the Field of Carbon Science. Frontiers in Microbiology, 8.

Azua-Bustos A., Gonzalez-Silva C., Fernandez-Martinez M. A., Arenas-Fajardo C., Fonseca R., Martin-Torres F. J., Fernandez-Sampedro M., Fairen A. G., and Zorzano M. P. (2019) Aeolian transport of viable microbial life across the Atacama Desert, Chile: Implications for Mars. Scientific Reports, 9.

Azua-Bustos A., Gonzalez-Silva C., Mancilla R. A., Salas L., Palma R. E., Wynne J. J., McKay C. P., and Vicuna R. (2009) Ancient Photosynthetic Eukaryote Biofilms in an Atacama Desert Coastal Cave. Microbial Ecology, 58: 485-496.

Azua-Bustos A., Urrejola C., and Vicuna R. (2012b) Life at the dry edge: Microorganisms of the Atacama Desert. Febs Letters, 586: 2939-2945.

Bagaley D. R. (2006) Uncovering bacterial diversity on and below the surface of a hyper-arid environment, the Atacama Desert, Chile: Louisiana State University and Agricultural and Mechanical College.

Balestra G. M., and Misaghi I. J. (1997) Increasing the efficiency of the plate counting method for estimating bacterial diversity. Journal of Microbiological Methods, 30: 111-117.

Barberan A., Bates S. T., Casamayor E. O., and Fierer N. (2012) Using network analysis to explore co-occurrence patterns in soil microbial communities. Isme Journal, 6: 343-351.

Barka E. A., Vatsa P., Sanchez L., Gaveau-Vaillant N., Jacquard C., Meier-Kolthoff J. P., Klenk H. P., Clement C., Ouhdouch Y., and van Wezel G. P. (2016) Taxonomy, Physiology, and Natural Products of Actinobacteria (vol 80, pg 1, 2016). Microbiology and Molecular Biology Reviews, 80: Iii-Iii.

Barros N., Feijoo S., Salgado J., Ramajo B., Garcia J. R., and Hansen L. D. (2008) The Dry Limit of Microbial Life in the Atacama Desert Revealed by Calorimetric Approaches. Engineering in Life Sciences, 8: 477-486.

Battista J. R., Earl A. M., and Park M. J. (1999) Why is Deinococcus radiodurans so resistant to ionizing radiation? Trends in Microbiology, 7: 362-365.

Battistuzzi F. U., and Hedges S. B. (2009) A Major Clade of Prokaryotes with Ancient Adaptations to Life on Land. Molecular Biology and Evolution, 26: 335-343.

Bokulich N. A., Dillon M. R., Bolyen E., Kaehler B. D., Huttley G. A., and Caporaso J. G. (2018) q2-sampleclassifier: machine-learning tools for microbiome classification and regression. J Open Res Softw, 3.

Bolyen E., Rideout J. R., Dillon M. R., Bokulich N. A., Abnet C. C., Al-Ghalith G. A., Alexander H., Alm E. J., Arumugam M., Asnicar F. and others. (2019) Reproducible, interactive, scalable and extensible microbiome data science using QIIME 2. Nat Biotechnol, 37: 852-857.

Bossio D. A., Scow K. M., Gunapala N., and Graham K. J. (1998) Determinants of soil microbial communities: Effects of agricultural management, season, and soil type on phospholipid fatty acid profiles. Microbial Ecology, 36: 1-12. 
Bull A. T., Asenjo J. A., Goodfellow M., and Gomez-Silva B. (2016) The Atacama Desert: Technical Resources and the Growing Importance of Novel Microbial Diversity. Annual Review of Microbiology, Vol 70, 70: 215-234.

Callahan B. J., McMurdie P. J., Rosen M. J., Han A. W., Johnson A. J. A., and Holmes S. P. (2016) DADA2: Highresolution sample inference from Illumina amplicon data. Nature Methods, 13: 581-+.

Cameron R. E. (1969) Abundance of microflora in soils of desert regions. NASA Technical Report, 32-1378: 1-16.

Caporaso J. G., Bittinger K., Bushman F. D., DeSantis T. Z., Andersen G. L., and Knight R. (2010a) PyNAST: a flexible tool for aligning sequences to a template alignment. Bioinformatics, 26: 266-267.

Caporaso J. G., Kuczynski J., Stombaugh J., Bittinger K., Bushman F. D., Costello E. K., Fierer N., Pena A. G., Goodrich J. K., Gordon J. I. and others. (2010b) QIIME allows analysis of high-throughput community sequencing data. Nature Methods, 7: 335-336.

Caporaso J. G., Lauber C. L., Walters W. A., Berg-Lyons D., Huntley J., Fierer N., Owens S. M., Betley J., Fraser L., Bauer M. and others. (2012) Ultra-high-throughput microbial community analysis on the Illumina HiSeq and MiSeq platforms. Isme Journal, 6: 1621-1624.

Caspi R., Billington R., Fulcher C. A., Keseler I. M., Kothari A., Krummenacker M., Latendresse M., Midford P. E., Ong Q., Ong W. K. and others. (2018) The MetaCyc database of metabolic pathways and enzymes. Nucleic Acids Res, 46: D633-D639.

Cereceda P., Larrain H., Osses P., Farias M., and Egana I. (2008) The climate of the coast and fog zone in the Tarapaca Region, Atacama Desert, Chile. Atmospheric Research, 87: 301-311.

Chevrier V., Hanley J., and Altheide T. (2009) Stability of perchlorate hydrates and their liquid solutions at the Phoenix landing site, Mars (vol 36, art no L10202, 2009). Geophysical Research Letters, 36.

Clark B. C., and Vanhart D. C. (1981) The Salts of Mars. Icarus, 45: 370-378.

Cockell C. S., Brown S., Landenmark H., Samuels T., Siddall R., and Wadsworth J. (2017) Liquid Water Restricts Habitability in Extreme Deserts. Astrobiology, 17: 309-318.

Coenye T., and Vandamme P. (2004) A genomic perspective on the relationship between the Aquificales and the epsilon-Proteobacteria. Systematic and Applied Microbiology, 27: 313-322.

Cole J. R., Wang Q., Fish J. A., Chai B. L., McGarrell D. M., Sun Y. N., Brown C. T., Porras-Alfaro A., Kuske C. R., and Tiedje J. M. (2014) Ribosomal Database Project: data and tools for high throughput rRNA analysis. Nucleic Acids Research, 42: D633-D642.

Connon S. A., Lester E. D., Shafaat H. S., Obenhuber D. C., and Ponce A. (2007) Bacterial diversity in hyperarid Atacama Desert soils. Journal of Geophysical Research-Biogeosciences, 112.

Contador C. A., Veas-Castillo L., Tapia E., Antipan M., Miranda N., Ruiz-Tagle B., Garcia-Araya J., Andrews B. A., Marin M., Dorador C. and others. (2019) Atacama Database: a platform of the microbiome of the Atacama Desert. Antonie Van Leeuwenhoek.

Cowan D. A., Russell N. J., Mamais A., and Sheppard D. M. (2002) Antarctic Dry Valley mineral soils contain unexpectedly high levels of microbial biomass. Extremophiles, 6: 431-436.

Csardi G., and Nepusz T. (2006) The igraph software package for complex network research. InterJournal, Complex Systems, 1695: 1-9.

Cull S. C., Arvidson R. E., Catalano J. G., Ming D. W., Morris R. V., Mellon M. T., and Lemmon M. (2010) Concentrated perchlorate at the Mars Phoenix landing site: Evidence for thin film liquid water on Mars. Geophysical Research Letters, 37.

Davila A. F., Gomez-Silva B., de los Rios A., Ascaso C., Olivares H., Mckay C. P., and Wierzchos J. (2008) Facilitation of endolithic microbial survival in the hyperarid core of the Atacama Desert by mineral deliquescence. Journal of Geophysical Research-Biogeosciences, 113.

Davila A. F., Hawes I., Ascaso C., and Wierzchos J. (2013) Salt deliquescence drives photosynthesis in the hyperarid Atacama Desert. Environmental Microbiology Reports, 5: 583-587.

Davis W. L., de Pater I., and McKay C. P. (2010) Rain infiltration and crust formation in the extreme arid zone of the Atacama Desert, Chile. Planetary and Space Science, 58: 616-622.

Deckert G., Warren P. V., Gaasterland T., Young W. G., Lenox A. L., Graham D. E., Overbeek R., Snead M. A., Keller M., Aujay M. and others. (1998) The complete genome of the hyperthermophilic bacterium Aquifex aeolicus. Nature, 392: 353-358.

Dion P. (2008) Microbiology of extreme soils.

DiRuggiero J., Wierzchos J., Robinson C. K., Souterre T., Ravel J., Artieda O., Souza-Egipsy V., and Ascaso C. (2013) Microbial colonisation of chasmoendolithic habitats in the hyper-arid zone of the Atacama Desert. Biogeosciences, 10: 2439-2450.

Doran J. W., Elliott E. T., and Paustian K. (1998) Soil microbial activity, nitrogen cycling, and long-term changes in organic carbon pools as related to fallow tillage management. Soil E Tillage Research, 49: 3-18. 
Dose K., Bieger-Dose A., Ernst B., Feister U., Gomez-Silva B., Klein A., Risi S., and Stridde C. (2001) Survival of microorganisms under the extreme conditions of the Atacama Desert. Origins of Life and Evolution of Biospheres, 31: 287-303.

Douglas G. M., Maffei V. J., Zaneveld J., Yurgel S. N., Brown J. R., Taylor C. M., Huttenhower C., and Langille M. G. (2019) PICRUSt2: An improved and extensible approach for metagenome inference. BioRxiv: 672295.

Drees K. P., Neilson J. W., Betancourt J. L., Quade J., Henderson D. A., Pryor B. M., and Maier R. M. (2006) Bacterial community structure in the hyperarid core of the Atacama Desert, Chile. Applied and Environmental Microbiology, 72: 7902-7908.

Drenovsky R. E., Vo D., Graham K. J., and Scow K. M. (2004) Soil water content and organic carbon availability are major determinants of soil microbial community composition. Microbial Ecology, 48: 424-430.

Edgar R. C., Haas B. J., Clemente J. C., Quince C., and Knight R. (2011) UCHIME improves sensitivity and speed of chimera detection. Bioinformatics, 27: 2194-2200.

Edwards C. (1990) Microbiology of extreme environments. Open University Press Milton Keynes.

Ericksen G. E. (1983) The Chilean Nitrate Deposits. American Scientist, 71: 366-374.

Ewing S. A., Macalady J. L., Warren-Rhodes K., McKay C. P., and Amundson R. (2008) Changes in the soil C cycle at the arid-hyperarid transition in the Atacama Desert. Journal of Geophysical Research-Biogeosciences, 113.

Ewing S. A., Michalski G., Thiemens M., Quinn R. C., Macalady J. L., Kohl S., Wankel S. D., Kendall C., Mckay C. P., and Amundson R. (2007) Rainfall limit of the N cycle on Earth. Global Biogeochemical Cycles, 21.

Faith D. P. (1992) Conservation Evaluation and Phylogenetic Diversity. Biological Conservation, 61: 1-10.

Farias M. E., Contreras M., Rasuk M. C., Kurth D., Flores M. R., Poire D. G., Novoa F., and Visscher P. T. (2014) Characterization of bacterial diversity associated with microbial mats, gypsum evaporites and carbonate microbialites in thalassic wetlands: Tebenquiche and La Brava, Salar de Atacama, Chile. Extremophiles, 18: 311-329.

Farias M. E., Rascovan N., Toneatti D. M., Albarracin V. H., Flores M. R., Poire D. G., Collavino M. M., Aguilar O. M., Vazquez M. P., and Polerecky L. (2013) The Discovery of Stromatolites Developing at $3570 \mathrm{~m}$ above Sea Level in a High-Altitude Volcanic Lake Socompa, Argentinean Andes. Plos One, 8.

Farias M. E., Rasuk M. C., Gallagher K. L., Contreras M., Kurth D., Fernandez A. B., Poire D., Novoa F., and Visscher P. T. (2017) Prokaryotic diversity and biogeochemical characteristics of benthic microbial ecosystems at La Brava, a hypersaline lake at Salar de Atacama, Chile. Plos One, 12.

Fernandez-Martinez M. A., Severino R. D., Moreno-Paz M., Gallardo-Carreno I., Blanco Y., Warren-Rhodes K., Garcia-Villadangos M., Ruiz-Bermejo M., Barberan A., Wettergreen D. and others. (2019) Prokaryotic Community Structure and Metabolisms in Shallow Subsurface of Atacama Desert Playas and Alluvial Fans After Heavy Rains: Repairing and Preparing for Next Dry Period. Frontiers in Microbiology, 10.

Fernandez A. B., Rasuk M. C., Visscher P. T., Contreras M., Novoa F., Poire D. G., Patterson M. M., Ventosa A., and Farias M. E. (2016) Microbial Diversity in Sediment Ecosystems (Evaporites Domes, Microbial Mats, and Crusts) of Hypersaline Laguna Tebenquiche, Salar de Atacama, Chile. Frontiers in Microbiology, 7.

Finlay B. J., Maberly S. C., and Cooper J. I. (1997) Microbial diversity and ecosystem function. Oikos, 80: 209-213. Finstad K. M., Probst A. J., Thomas B. C., Andersen G. L., Demergasso C., Echeverria A., Amundson R. G., and Banfield J. F. (2017) Microbial Community Structure and the Persistence of Cyanobacterial Populations in Salt Crusts of the Hyperarid Atacama Desert from Genome-Resolved Metagenomics. Frontiers in Microbiology, 8.

Francaviglia R. (2016) The Atacama Desert: A Five Hundred Year Journey of Discovery. Terrae Incognitae-the Journal of the Society for the History of Discoveries, 48: 105-138.

Gallardo A., and Schlesinger W. H. (1992) Carbon and Nitrogen Limitations of Soil Microbial Biomass in Desert Ecosystems. Biogeochemistry, 18: 1-17.

Goldstein A. H., Braverman K., and Osorio N. (1999) Evidence for mutualism between a plant growing in a phosphate-limited desert environment and a mineral phosphate solubilizing (MPS) rhizobacterium. Fems Microbiology Ecology, 30: 295-300.

Gómez-Silva B., Rainey F. A., Warren-Rhodes K. A., McKay C. P., and Navarro-González R. (2008) Atacama Desert soil microbiology. In: Microbiology of extreme soils, Springer, Berlin, Heidelberg, pp 117-132.

Goodfellow M., Nouioui I., Sanderson R., Xie F. Y., and Bull A. T. (2018) Rare taxa and dark microbial matter: novel bioactive actinobacteria abound in Atacama Desert soils. Antonie Van Leeuwenhoek International Journal of General and Molecular Microbiology, 111: 1315-1332.

Griffiths E., and Gupta R. S. (2006) Molecular signatures in protein sequences that are characteristics of the phylum Aquificae. International Journal of Systematic and Evolutionary Microbiology, 56: 99-107.

Gupta R. S., and Lali R. (2013) Molecular signatures for the phylum Aquificae and its different clades: proposal for division of the phylum Aquificae into the emended order Aquificales, containing the families Aquificaceae and Hydrogenothermaceae, and a new order Desulfurobacteriales ord. nov., containing the 
family Desulfurobacteriaceae. Antonie Van Leeuwenhoek International Journal of General and Molecular Microbiology, 104: 349-368.

Hammer Ø., Harper D. A., and Ryan P. D. (2001) PAST: paleontological statistics software package for education and data analysis. Palaeontologia electronica, 4: 9.

Hansen A. A., Herbert R. A., Mikkelsen K., Jensen L. L., Kristoffersen T., Tiedje J. M., Lomstein B. A., and Finster K. W. (2007) Viability, diversity and composition of the bacterial community in a high Arctic permafrost soil from Spitsbergen, Northern Norway. Environmental Microbiology, 9: 2870-2884.

Hao L. P., McIlroy S. J., Kirkegaard R. H., Karst S. M., Fernando W. E. Y., Aslan H., Meyer R. L., Albertsen M., Nielsen P. H., and Dueholm M. S. (2018) Novel prosthecate bacteria from the candidate phylum Acetothermia. Isme Journal, 12: 2225-2237.

Harrell F. E. (2019) Hmisc: Harrell miscellaneous. R package version 4.3-0.

Harris J. K., Cousins C. R., and Claire M. W. (2016) Spectral identification and quantification of salts in the Atacama Desert. Earth Resources and Environmental Remote Sensing/Gis Applications Vii, 10005.

Hartley A. J., Chong G., Houston J., and Mather A. E. (2005) 150 million years of climatic stability: evidence from the Atacama Desert, northern Chile. Journal of the Geological Society, 162: 421-424.

Heldmann J. L., Conley C. A., Brown A. J., Fletcher L., Bishop J. L., and McKay C. P. (2010) Possible liquid water origin for Atacama Desert mudflow and recent gully deposits on Mars. Icarus, 206: 685-690.

Herlemann D. P. R., Labrenz M., Jurgens K., Bertilsson S., Waniek J. J., and Andersson A. F. (2011) Transitions in bacterial communities along the $2000 \mathrm{~km}$ salinity gradient of the Baltic Sea. Isme Journal, 5: 1571-1579.

Holmes A. J., Bowyer J., Holley M. P., O'Donoghue M., Montgomery M., and Gillings M. R. (2000) Diverse, yetto-be-cultured members of the Rubrobacter subdivision of the Actinobacteria are widespread in Australian arid soils. Fems Microbiology Ecology, 33: 111-120.

Horiike T., Miyata D., Hamada K., Saruhashi S., Shinozawa T., Kumar S., Chakraborty R., Komiyama T., and Tateno Y. (2009) Phylogenetic construction of 17 bacterial phyla by new method and carefully selected orthologs. Gene, 429: 59-64.

Houston J. (2006) Variability of precipitation in the Atacama desert: Its causes and hydrological impact. International Journal of Climatology, 26: 2181-2198.

Houston J., and Hartley A. J. (2003) The central andean west-slope rainshadow and its potential contribution to the origin of HYPER-ARIDITY in the Atacama desert. International Journal of Climatology, 23: 1453-1464.

Huang Q. Y., Dong C. Z., Dong R. M., Jiang H. C., Wang S., Wang G. H., Fang B., Ding X. X., Niu L., Li X. and others. (2011) Archaeal and bacterial diversity in hot springs on the Tibetan Plateau, China. Extremophiles, 15: 549-563.

Huber R., Wilharm T., Huber D., Trincone A., Burggraf S., Konig H., Rachel R., Rockinger I., Fricke H., and Stetter K. O. (1992) Aquifex-Pyrophilus Gen-Nov Sp-Nov Represents a Novel Group of Marine Hyperthermophilic Hydrogen-Oxidizing Bacteria. Systematic and Applied Microbiology, 15: 340-351.

Hugler M., Huber H., Molyneaux S. J., Vetriani C., and Sievert S. M. (2007) Autotrophic CO2 fixation via the reductive tricarboxylic acid cycle in different lineages within the phylum Aquificae: evidence for two ways of citrate cleavage. Environmental Microbiology, 9: 81-92.

Hullar M. A. J., Fry B., Peterson B. J., and Wright R. T. (1996) Microbial utilization of estuarine dissolved organic carbon: A stable isotope tracer approach tested by mass balance. Applied and Environmental Microbiology, 62: 2489-2493.

Idris H., Goodfellow M., Sanderson R., Asenjo J. A., and Bull A. T. (2017) Actinobacterial Rare Biospheres and Dark Matter Revealed in Habitats of the Chilean Atacama Desert. Scientific Reports, 7.

Illumina®. (2013) 16S Metagenomic Sequencing Library Preparation.

Janssen P. H., Yates P. S., Grinton B. E., Taylor P. M., and Sait M. (2002) Improved culturability of soil bacteria and isolation in pure culture of novel members of the divisions Acidobacteria, Actinobacteria, Proteobacteria, and Verrucomicrobia. Applied and Environmental Microbiology, 68: 2391-2396.

Jones D. L., Olivera-Ardid S., Klumpp E., Knief C., Huil P. W., Lehndorff E., and Bol R. (2018) Moisture activation and carbon use efficiency of soil microbial communities along an aridity gradient in the Atacama Desert. Soil Biology \& Biochemistry, 117: 68-71.

Jones J. G. (1971) Studies on Freshwater Bacteria - Factors Which Influence Population and Its Activity. Journal of Ecology, 59: 593-\&.

Jordan T. E., Herrera C., Godfrey L. V., Colucci S. J., Gamboa C., Urrutia J., Gonzalez G., and Paul J. F. (2019) Isotopic characteristics and paleoclimate implications of the extreme precipitation event of March 2015 in northern Chile. Andean Geology, 46: 1-31.

Jungbluth S. P., Amend J. P., and Rappe M. S. (2017) Metagenome sequencing and 98 microbial genomes from Juan de Fuca Ridge flank subsurface fluids (vol 4, 170037, 2017). Scientific Data, 4. 
Junker B. H., and Schreiber F. (2008) Correlation Networks. Wiley Online Library, Hoboken, NJ.

Kereszturi A., and Rivera-Valentin E. G. (2012) Locations of thin liquid water layers on present-day Mars. Icarus, 221: 289-295.

Klindworth A., Pruesse E., Schweer T., Peplies J., Quast C., Horn M., and Glockner F. O. (2013) Evaluation of general 16S ribosomal RNA gene PCR primers for classical and next-generation sequencing-based diversity studies. Nucleic Acids Research, 41.

Knief C., Bol R., Amelung W., Kusch S., Frindte K., Eckmeier E., Jaeschke A., Dunai T., Fuentes B., and Mörchen R. (2019) Tracing elevational changes in microbial life and organic carbon sources in soils of the Atacama Desert. Global and Planetary Change, 184: 103078.

Kounaves S. P., Carrier B. L., O'Neil G. D., Stroble S. T., and Claire M. W. (2014) Evidence of martian perchlorate, chlorate, and nitrate in Mars meteorite EETA79001: Implications for oxidants and organics. Icarus, 229: 206213.

L'Haridon S., Reysenbach A. L., Tindall B. J., Schonheit P., Banta A., Johnsen U., Schumann P., Gambacorta A., Stackebrandt E., and Jeanthon C. (2006) Desulfurobacterium atlanticum sp nov., Desulfurobacterium pacificum sp nov and Thermovibrio guaymasensis sp nov., three thermophilic members of the Desulfurobacteriaceae fam. nov., a deep branching lineage within the Bacteria. International Journal of Systematic and Evolutionary Microbiology, 56: 2843-2852.

Lee K. C., Dunfield P. F., and Stott M. B. (2014) The Phylum Armatimonadetes. The Prokaryotes: Other Major Lineages of Bacteria and The Archaea: 447-458.

Lester E. D., Satomi M., and Ponce A. (2007) Microflora of extreme arid Atacama Desert soils. Soil Biology E Biochemistry, 39: 704-708.

Ley R. E., Harris J. K., Wilcox J., Spear J. R., Miller S. R., Bebout B. M., Maresca J. A., Bryant D. A., Sogin M. L., and Pace N. R. (2006) Unexpected diversity and complexity of the Guerrero Negro hypersaline microbial mat. Applied and Environmental Microbiology, 72: 3685-3695.

Ma R. P., Xu J. Y., Wang W. B., and Yuan W. (2009) Seasonal and latitudinal differences of the saturation effect between ionospheric NmF2 and solar activity indices. Journal of Geophysical Research-Space Physics, 114.

Maier R. M., Drees K. P., Neilson J. W., Henderson D. A., Quade J., and Betancourt J. L. (2004) Microbial life in the Atacama Desert. Science, 306: 1289-1289.

Mandakovic D., Maldonado J., Pulgar R., Cabrera P., Gaete A., Urtuvia V., Seeger M., Cambiazo V., and Gonzalez M. (2018) Microbiome analysis and bacterial isolation from Lejia Lake soil in Atacama Desert. Extremophiles, 22: 665-673.

Mandal S., Van Treuren W., White R. A., Eggesbo M., Knight R., and Peddada S. D. (2015) Analysis of composition of microbiomes: a novel method for studying microbial composition. Microb Ecol Health Dis, 26: 27663.

Marion G. M., Verburg P. S. J., McDonald E. V., and Arnone J. A. (2008) Modeling salt movement through a Mojave Desert soil. Journal of Arid Environments, 72: 1012-1033.

Martin-Torres F. J., Zorzano M. P., Valentin-Serrano P., Harri A. M., Genzer M., Kemppinen O., Rivera-Valentin E. G., Jun I., Wray J., Madsen M. B. and others. (2015) Transient liquid water and water activity at Gale crater on Mars. Nature Geoscience, 8: 357-361.

Martinez G. M., and Renno N. O. (2013) Water and Brines on Mars: Current Evidence and Implications for MSL. Space Science Reviews, 175: 29-51.

McKay C. P., Friedmann E. I., Gomez-Silva B., Caceres-Villanueva L., Andersen D. T., and Landheim R. (2003) Temperature and moisture conditions for life in the extreme arid region of the Atacama Desert: Four years of observations including the El Nino of 1997-1998. Astrobiology, 3: 393-406.

Meslier V., Casero M. C., Dailey M., Wierzchos J., Ascaso C., Artieda O., McCullough P. R., and DiRuggiero J. (2018) Fundamental drivers for endolithic microbial community assemblies in the hyperarid Atacama Desert. Environmental Microbiology, 20: 1765-1781.

Meslin P. Y., Gasnault O., Forni O., Schroder S., Cousin A., Berger G., Clegg S. M., Lasue J., Maurice S., Sautter V. and others. (2013) Soil Diversity and Hydration as Observed by ChemCam at Gale Crater, Mars. Science, 341.

Miyamoto-Shinohara Y., Imaizumi T., Sukenobe J., Murakami Y., Kawamura S., and Komatsu Y. (2000) Survival rate of microbes after freeze-drying and long-term storage. Cryobiology, 41: 251-255.

Mobberley J. M., Ortega M. C., and Foster J. S. (2012) Comparative microbial diversity analyses of modern marine thrombolitic mats by barcoded pyrosequencing. Environmental Microbiology, 14: 82-100.

Morgan C. A., Herman N., White P. A., and Vesey G. (2006) Preservation of micro-organisms by drying; A review. Journal of Microbiological Methods, 66: 183-193. 
Navarro-Gonzalez R., Rainey F. A., Molina P., Bagaley D. R., Hollen B. J., de la Rosa J., Small A. M., Quinn R. C., Grunthaner F. J., Caceres L. and others. (2003) Mars-like soils in the Atacama Desert, Chile, and the dry limit of microbial life. Science, 302: 1018-1021.

Neilson J. W., Califf K., Cardona C., Copeland A., van Treuren W., Josephson K. L., Knight R., Gilbert J. A., Quade J., Caporaso J. G. and others. (2017) Significant Impacts of Increasing Aridity on the Arid Soil Microbiome. Msystems, 2.

Neilson J. W., Quade J., Ortiz M., Nelson W. M., Legatzki A., Tian F., LaComb M., Betancourt J. L., Wing R. A., Soderlund C. A. and others. (2012) Life at the hyperarid margin: novel bacterial diversity in arid soils of the Atacama Desert, Chile. Extremophiles, 16: 553-566.

Newman M. E. J. (2003) The structure and function of complex networks. Siam Review, 45: 167-256.

Omelchenko M. V., Wolf Y. I., Gaidamakova E. K., Matrosova V. Y., Vasilenko A., Zhai M., Daly M. J., Koonin E. V., and Makarova K. S. (2005) Comparative genomics of Thermus thermophilus and Deinococcus radiodurans: divergent routes of adaptation to thermophily and radiation resistance. Bmc Evolutionary Biology, 5 .

Palacio S., Azorin J., Montserrat-Marti G., and Ferrio J. P. (2014) The crystallization water of gypsum rocks is a relevant water source for plants. Nature Communications, 5.

Parinkina O. (1973) Determination of bacterial growth rates in tundra soils. Bulletins from the Ecological Research Committee: 303-309.

Paulino-Lima I. G., Azua-Bustos A., Vicuna R., Gonzalez-Silva C., Salas L., Teixeira L., Rosado A., Leitao A. A. D., and Lage C. (2013) Isolation of UVC-Tolerant Bacteria from the Hyperarid Atacama Desert, Chile. Microbial Ecology, 65: 325-335.

Paulino-Lima I. G., Fujishima K., Navarrete J. U., Galante D., Rodrigues F., Azua-Bustos A., and Rothschild L. J. (2016) Extremely high UV-C radiation resistant microorganisms from desert environments with different manganese concentrations. Journal of Photochemistry and Photobiology B-Biology, 163: 327-336.

Perfumo A., Cockell C., Elsaesser A., Marchant R., and Kminek G. (2011) Microbial diversity in Calamita ferromagnetic sand. Environmental Microbiology Reports, 3: 483-490.

Pfeiffer M., Latorre C., Gayo E., and Amundson R. (2019) Rare calcium chloride-rich soil and implications for the existence of liquid water in a hyperarid environment. Geology, 47: 163-166.

Phelps T. J., Murphy E. M., Pfiffner S. M., and White D. C. (1994) Comparison between Geochemical and Biological Estimates of Subsurface Microbial Activities. Microbial Ecology, 28: 335-349.

Pointing S. B., Chan Y. K., Lacap D. C., Lau M. C. Y., Jurgens J. A., and Farrell R. L. (2009) Highly specialized microbial diversity in hyper-arid polar desert. Proceedings of the National Academy of Sciences of the United States of America, 106: 19964-19969.

Prieto-Barajas C. M., Valencia-Cantero E., and Santoyo G. (2018) Microbial mat ecosystems: Structure types, functional diversity, and biotechnological application. Electronic Journal of Biotechnology, 31: 48-56.

Pruett C. J. H., Burges H. D., and Wyborn C. H. (1980) Effect of Exposure to Soil on Potency and Spore Viability of Bacillus-Thuringiensis. Journal of Invertebrate Pathology, 35: 168-174.

Puente M. E., Li C. Y., and Bashan Y. (2009) Endophytic bacteria in cacti seeds can improve the development of cactus seedlings. Environmental and Experimental Botany, 66: 402-408.

Quast C., Pruesse E., Yilmaz P., Gerken J., Schweer T., Yarza P., Peplies J., and Glockner F. O. (2013) The SILVA ribosomal RNA gene database project: improved data processing and web-based tools. Nucleic Acids Research, 41: D590-D596.

Quinn R. C., Ehrenfreund P., Grunthaner F. J., Taylor C. L., and Zent A. P. (2007) Decomposition of aqueous organic compounds in the Atacama Desert and in Martian soils. Journal of Geophysical Research-Biogeosciences, 112.

Quinn R. C., Zent A. P., Grunthaner F. J., Ehrenfreund P., Taylor C. L., and Garry J. R. C. (2005) Detection and characterization of oxidizing acids in the Atacama Desert using the Mars Oxidation Instrument. Planetary and Space Science, 53: 1376-1388.

Ramirez R. M., and Craddock R. A. (2018) The geological and climatological case for a warmer and wetter early Mars. Nature Geoscience, 11: 230-237.

Rasuk M. C., Fernandez A. B., Kurth D., Contreras M., Novoa F., Poire D., and Farias M. E. (2016) Bacterial Diversity in Microbial Mats and Sediments from the Atacama Desert. Microbial Ecology, 71: 44-56.

Rasuk M. C., Kurth D., Flores M. R., Contreras M., Novoa F., Poire D., and Farias M. E. (2014) Microbial Characterization of Microbial Ecosystems Associated to Evaporites Domes of Gypsum in Salar de Llamara in Atacama Desert. Microbial Ecology, 68: 483-494.

Reynolds J. F., Kemp P. R., Ogle K., and Fernandez R. J. (2004) Modifying the 'pulse-reserve' paradigm for deserts of North America: precipitation pulses, soil water, and plant responses. Oecologia, 141: 194-210. 
Rognes T., Flouri T., Nichols B., Quince C., and Mahe F. (2016) VSEARCH: a versatile open source tool for metagenomics. Peerj, 4.

Roldan M., Ascaso C., and Wierzchos J. (2014) Fluorescent Fingerprints of Endolithic Phototrophic Cyanobacteria Living within Halite Rocks in the Atacama Desert. Applied and Environmental Microbiology, 80: 2998-3006.

Rose H. L., Dewey C. A., Ely M. S., Willoughby S. L., Parsons T. M., Cox V., Spencer P. M., and Weller S. A. (2011) Comparison of Eight Methods for the Extraction of Bacillus atrophaeus Spore DNA from Eleven Common Interferents and a Common Swab. Plos One, 6.

Sahl J. W., Pace N. R., and Spear J. R. (2008) Comparative molecular analysis of endoevaporitic microbial communities. Applied and Environmental Microbiology, 74: 6444-6446.

Saul-Tcherkas V., and Steinberger Y. (2011) Soil Microbial Diversity in the Vicinity of a Negev Desert ShrubReaumuria negevensis. Microbial Ecology, 61: 64-81.

Schulze-Makuch D., Wagner D., Kounaves S. P., Mangelsdorf K., Devine K. G., de Vera J. P., Schmitt-Kopplin P., Grossart H. P., Parro V., Kaupenjohann M. and others. (2018) Transitory microbial habitat in the hyperarid Atacama Desert. Proceedings of the National Academy of Sciences of the United States of America, 115: 2670-2675.

Schwinning S., Sala O. E., Loik M. E., and Ehleringer J. R. (2004) Thresholds, memory, and seasonality: understanding pulse dynamics in arid/semi-arid ecosystems. Oecologia, 141: 191-193.

Shen J., Zerkle A., Stueeken E., and Claire M. (2019) Nitrates as a Potential N Supply for Microbial Ecosystems in a Hyperarid Mars Analog System. Life, 9: 79.

Shi T., Reeves R. H., Gilichinsky D. A., and Friedmann E. I. (1997) Characterization of viable bacteria from Siberian permafrost by $16 \mathrm{~S}$ rDNA sequencing. Microbial Ecology, 33: 169-179.

Shirey T. B., Thacker R. W., and Olson J. B. (2012) Composition and stability of bacterial communities associated with granular activated carbon and anthracite filters in a pilot scale municipal drinking water treatment facility. Journal of Water and Health, 10: 244-255.

Sieuwerts S., de Bok F. A. M., Mols E., de Vos W. M., and Vlieg J. E. T. V. (2008) A simple and fast method for determining colony forming units. Letters in Applied Microbiology, 47: 275-278.

Smith J. J., Tow L. A., Stafford W., Cary C., and Cowan D. A. (2006) Bacterial diversity in three different Antarctic cold desert mineral soils. Microbial Ecology, 51: 413-421.

Stepinski T. F., and Stepinski A. P. (2005) Morphology of drainage basins as an indicator of climate on early Mars. Journal of Geophysical Research-Planets, 110.

Stevenson A., Burkhardt J., Cockell C. S., Cray J. A., Dijksterhuis J., Fox-Powell M., Kee T. P., Kminek G., McGenity T. J., Timmis K. N. and others. (2015) Multiplication of microbes below 0.690 water activity: implications for terrestrial and extraterrestrial life. Environmental Microbiology, 17: 257-277.

Sun T., Bao H. M., Reich M., and Hemming S. R. (2018) More than ten million years of hyper-aridity recorded in the Atacama Gravels. Geochimica Et Cosmochimica Acta, 227: 123-132.

Trewartha G. (1981) The Earth's Problem Climates. University of Wisconsin Press, Madison, Wisconsin, USA.

Uritskiy G., Getsin S., Munn A., Gomez-Silva B., Davila A., Glass B., Taylor J., and DiRuggiero J. (2019) Halophilic microbial community compositional shift after a rare rainfall in the Atacama Desert. ISME J.

Warren-Rhodes K. A., Lee K. C., Archer S. D. J., Cabrol N., Ng-Boyle L., Wettergreen D., Zacny K., Pointing S. B., Chong G., Demargasso C. and others. (2019) Subsurface Microbial Habitats in an Extreme Desert MarsAnalog Environment. Frontiers in Microbiology, 10.

Warren-Rhodes K. A., Rhodes K. L., Pointing S. B., Ewing S. A., Lacap D. C., Gomez-Silva B., Amundson R., Friedmann E. I., and McKay C. P. (2006) Hypolithic cyanobacteria, dry limit of photosynthesis, and microbial ecology in the hyperarid Atacama Desert. Microbial Ecology, 52: 389-398.

Wierzchos J., Camara B., De Los Rios A., Davila A. F., Almazo I. M. S., Artieda O., Wierzchos K., Gomez-Silva B., Mckay C., and Ascaso C. (2011) Microbial colonization of Ca-sulfate crusts in the hyperarid core of the Atacama Desert: implications for the search for life on Mars. Geobiology, 9: 44-60.

Wierzchos J., Davila A. F., Sanchez-Almazo I. M., Hajnos M., Swieboda R., and Ascaso C. (2012) Novel water source for endolithic life in the hyperarid core of the Atacama Desert. Biogeosciences, 9: 2275-2286.

Wood J. M. (2015) Bacterial responses to osmotic challenges. Journal of General Physiology, 145: 381-388.

Zahran H. H. (1997) Diversity, adaptation and activity of the bacterial flora in saline environments. Biology and Fertility of Soils, 25: 211-223.

Zeglin L. H., Sinsabaugh R. L., Barrett J. E., Gooseff M. N., and Takacs-Vesbach C. D. (2009) Landscape Distribution of Microbial Activity in the McMurdo Dry Valleys: Linked Biotic Processes, Hydrology, and Geochemistry in a Cold Desert Ecosystem. Ecosystems, 12: 562-573. 